Max-Planck-Institut für demografische Forschung

Max Planck Institute for Demographic Research

Doberaner Strasse $114 \cdot$ D-18057 Rostock $\cdot$ GERMANY

Tel +49 (0) 3812081 - 0; Fax +49 (0) 3812081 - 202;

http://www.demogr.mpg.de

MPIDR WORKING PAPER WP 2002-019

MAY 2002

\title{
Differences in Lifespan by Month of Birth for the United States: \\ The impact of early life events and conditions on late life mortality
}

Gabriele Doblhammer (doblhammer@demogr.mpg.de)

This working paper has been approved for release by: James W. Vaupel (jwv@demogr.mpg.de) Head of the Laboratory of Survival and Longevity.

(C) Copyright is held by the authors.

Working papers of the Max Planck Institute for Demographic Research receive only limited review. Views or opinions expressed in working papers are attributable to the authors and do not necessarily reflect those of the Institute. 


\begin{abstract}
We find significant differences in the mean age at death by month of birth on the basis of 15 million US death certificates for the years 1989 to 1997: those born in fall live about 0.44 of a year longer than those born in spring. The difference depends on race, region of birth, marital status, and education: the differences are largest for the less educated, for those who have never been married and for blacks, and the differences are more marked in the South than in the North. They are only slightly larger for males than for females. For blacks, the shape of the month-of-birth pattern is significantly different from that of whites. We present evidence that this difference is due to whether one has an urban or a rural place of birth.

We find a significant month-of-birth pattern for all major causes of death including cardiovascular disease, malignant neoplasms, in particular lung cancer, and other natural diseases like chronic obstructive lung disease, or infectious disease.

We reject the hypotheses that the differences in life span by month of birth are caused by seasonal differences in daylight or by seasonal differences in temperature. Our results are consistent with the explanation that seasonal differences in nutrition of the mother during pregnancy and seasonal differences in the exposure to infectious disease early in life lead to the differences in lifespan by month of birth.
\end{abstract}




\section{Introduction}

The most important criticism about research on early life environment and later life health and mortality is concerned with how this research is interpreted (for an overview see Kuh \& Davey Smith 1993). It has been argued that the strong correlation between early environment and adult mortality may simply be an effect of continued deprivation over the whole life course rather than of factors that act early in life (Ben-Shlomo \& Davey Smith 1991).

We use month of birth as an indicator for early life circumstances. In an earlier article we have shown that month of birth does not have any further life course interpretations that affect mortality (Doblhammer \& Vaupel 2001). By comparing the pattern for people born in the Northern Hemisphere to those born in the Southern Hemisphere we have also shown that the effect of the month of birth on life span is related to the seasons of the year. In both hemispheres, the remaining life expectancy after age 50 is lower for people born in spring than for those born in fall. Thus, in the Northern Hemisphere the pattern is a mirror image of the Southern Hemisphere's pattern. Furthermore, we showed that a significant positive correlation exists between infant mortality in the first year of life by month of birth and mean age at death by month of birth. This led us to the conclusion that it is debilitation rather than selection that leads to the differences in life span by month of birth.

The aim of this article is to gain deeper insights into the mechanisms that cause the differences in life span by month of birth by using information about the social, demographic and geographic characteristics of the decedents. We explore whether the differences vary with educational background, marriage status, region of birth, race and sex on the basis of 15.6 million US death certificates for the years 1989 to 1997 . We expect that the differences depend on social factors: they should increase with lower education and they should be larger for African-Americans than for whites. Evidence exists that marital status is partly determined by health selection into marriage (Goldman, Lord \& $\mathrm{Hu} 1993$ ) and that the never married are frailer than the ever-married population (Goldman \& Hu 1993). Differences in life span by month of birth should therefore be larger among the never married than among the ever married. 
The information about state of birth permits us to test four hypotheses that have been put forward to explain the month-of-birth effect. The state of birth provides information about the approximate latitude of birth and thus the seasonal differences in the hours of daylight. It has been shown that the seasonal changes in the hours of daylight influence the human neuroendocrine functions (Wehr 1998). Several researchers have postulated that the winter-spring birth excess observed in schizophrenia and bi-polar disorders might be caused by variations in internal chemistry or neural development brought about by seasonal variations in light (Turnquist 1993, Quested 1991, Morgan 1978, Jongbloet 1975 and Pallast et al. 1994). If the effect of month of birth on mortality later in life is due to seasonal differences in daylight, then the effect should be correlated with latitude and should be smaller in the southern part of the US than in the northern part.

The state of birth provides information about the prevailing macro climate. According to the widely used Köppen classification (Köppen 1936), the United States consists of six major climatic zones. Regions between 30 and 60 degrees North latitude belong to the humid continental climate zone characterized by changeable weather, hot summers and cold winters. On the eastern side of the continent between 20 and 35 degrees North latitude, the humid subtropical climate prevails. This climate is characterized by uniform precipitation throughout the year with moist and hot summers and mild winters. The mild-latitude steppe and desert climate are found in the continental interior and include the tropical and subtropical steppe climates in the south. Temperature conditions are extremely variable, with the annual means decreasing and the annual range increasing to the North. In the higher latitudes, winters are severely cold with meager precipitation. In the South the tropical and subtropical steppe climate is located primarily on the periphery of true deserts. The Mediterranean Climate of Southern California features hot dry summers and cool wet winters. The Marine west coast climate, which extends between 35 and 60 degrees North latitude, is characterized by ample precipitation in all months, small annual temperature ranges, mild winters and moderate summers with rarely more than 20 degrees Celsius. This area is confined to a narrow coastal strip of the West Coast. 
Seasonal differences in temperature depend on the climate. Huntington (1936) was one of the first to formulate the hypothesis that temperature, in particular high temperature at the time of conception, causes the differences in life span by weakening the "germ plasma".

".....season of birth is related to length of life primarily, although perhaps not wholly, through the condition of the parents and hence of the germ plasma at the time of conception. This by no means excludes the hypothesis of a permanent depressive effect when a very young infant experiences undue heat or disease regardless of any selection through death (page 186)".

More recent research has shown that the sperm quality of male outside workers decreases during periods of high temperature (Centola \& Eberly 1999). Pasamanick (1986) proposed that hot summers were the cause of protein deficiency at the time of conception. As temperatures are generally highest in July/August, infants born in March and April should experience the lowest life expectancy. The peak-to-trough difference should be largest in regions with high summer temperatures.

The third hypothesis is that infectious disease causes the differences in life span by month of birth. The information about state of birth is linked to the burden of infectious diseases through climate. Climate influences the incidence of infectious diseases through temperature, humidity, precipitation in the form of normal and severe rainfall, wind and ocean currents. Thus, the incidence of infectious disease is generally highly seasonal. Among the vectorborn diseases e.g. malaria and dengue fever were once common in the southern United States. The incidence of waterborne diseases, which account for as much as 80 percent of the annual mortality due to infectious diseases (Clark, 1993), is correlated with warmer temperatures and flooding (Colwell 1996, Gueri, Gonzalea \& Morin 1986). Transmission of infections via food through viruses, bacteris or protozoa causes significant illness. Campylobacteriosis is a common diarrheal disease of bacterial origin which is generally acquired by drinking contaminated milk or water or by eating improperly cooked meat or fowl. There is a pronounced seasonality in its incidence since it normally occurs during the spring (Korlath et al. 1985). The incidence of other foodborne diseases, like salmonella enteritidis (Shears \& Wright 1985) or cyclospora cayetanenis (Madico et al. 1997), coincide with peak climatological 
temperatures. The seasonal variability of many respiratory diseases suggests the existence of a weather-related factor in the transmission of airborne diseases. The respiratory syncytial virus, which peaks in the fall (Shears \& Wright 1995), commonly causes bronchitis and mild upper respiratory tract infections that can result in severe, and even fatal lower tract problems, especially among infants.

The southern part of the US should have been an unhealthier environment for infants (when controlled for urban/rural residence, race and socioeconomic status) because of a higher incidence of infectious and parasitic disease and gastroenteritis. An increase in the peak-to-trough difference from north to south would thus suggest that infectious disease plays a major role.

On the other hand, the respiratory diseases, which early in life are mainly caused by seasonal virus infections, were spread more in the poorly ventilated conditions accompanying winters in the $\operatorname{North}^{1}$ (Preston \& Haines 1991).

The fourth hypothesis is that nutrition of the mother during pregnancy and of the baby in the first year of life is the causal mechanism that underlies the month-of-birth pattern. Diet is the result of a complex interaction of social, economic and environmental factors. At the beginning of the $20^{\text {th }}$ century, large regional differences in diet existed in the US. What the different diets had in common was that they do not resemble contemporary US dietary patterns (Levenstein 1988, 1993). People ate meat -- either fresh meat in the middle or upper classes, or salted meat among the poor -- with potatoes or another starchy, staple food. Other vegetables and fruits took up a niche on their table. The first vitamin was only discovered in 1911; in the early 1900s nutritionists were even opposed to greens, which were thought to require more bodily energy for digestion than they provided (Dyson 2000). With the notable exception of the South, there is no indication that even the poorest workers suffered from insufficient quantities of food. The problem was rather the quality and the variety, especially during winter and spring, when affordable supplies dried up. As mentioned above, there were large regional differences

${ }^{1}$. In the text we refer to New England, Middle Atlantic, East North Central, West North Central as the North; to South Atlantic, East South Central and West South Central as the South; Mountain and Pacific as the West. 
in diet. Diet was particularly poor in the rural South, where farmers -- many of whom were tenant farmers -- survived on the "three M's", that is, meat (salted pork), meal (mainly corn meal) and molasses. Sharecroppers moved too frequently to develop their own vegetable gardens or to raise their own livestock. As a result, milk and fresh meat, even fresh pork, were usually rarities on croppers' tables. The tenancy system discouraged the production of non-cash crops and tenants depended on the sale of flour, molasses, sugar and salt pork, which mainly came from the large meat factories in Chicago. In the summer time, greens and berries could be gathered, but the hard work required during planting time in the spring and harvest time from August to December, normally inhibited those endeavors, particularly in the cotton belt (Levenstein 1993). Contemporary dietary studies have shown that, particularly in winter and early spring, diets in the rural South lacked variety whereas better nutrition and a wider variety of foods was shown to exist in the urban South (Dirks \& Duran 2001).

In summary, in the North and in urban areas people suffered from seasonal deficiencies in nutrients while in the rural South they experienced deficient nutrition during the whole year with downright malnutrition in winter and early spring.

The effects of region of birth, race, and education are inherently confounded. There are two other confounding factors, namely age and cohort. Our analysis shows that differences in life span by month-of-birth are smaller in the more recent cohorts (Doblhammer \& Vaupel 2001) and that they become smaller with age (unpublished manuscript). We cannot distinguish between age and cohort effects because of the crosssectional nature of the death records. However, we age standardize the calculations when we analyze the data by univariate methods and we control for the main effects of sex, education, race and region on age at death when we use multivariate methods.

\section{Data}

We use the publicly available Multiple Cause of Death Data for the years 1989 to 1997 from the National Center for Health Statistics (NCHS) to which the information about month of birth was added. This study consists of 15,596,952 death records for all black and white US-born decedents who died in the United States between 1989 and 1997. Table 1 gives an overview of the data regarding mean age at death and the proportion of 
the decedents that fall into the different categories of education, marriage status, race and region of birth.

We distinguish between two educational groups: the 5.3 million decedents with a basic education have less than a high school education or did not finish high school (up to eleven years of education); the 8.2 million decedents with a high education have at least finished high school. There is also a residual group of 2.2 million death records with an unknown educational level. We restricted the analysis to blacks and whites to guarantee that a sufficient number of deaths were given for each month of birth. The states of birth are grouped according to the grouping in the death records into the nine regions of New England, Middle Atlantic, East North Central, West North Central, South Atlantic, East South Central, West South Central, Mountain and Pacific; Hawaii and Alaska are excluded.

Data on mean temperature by state for the years 1895 to 2001 come from the NOAA-CIRES Climate Diagnostic Center. The file is provided online and updated monthly. The statewide values are available for the 48 contiguous states and are computed from the divisional values weighted by area (Karl \& Koss 1984).

Latitude and longitude for the centers of population of the 48 contiguous states in the year 2000 are provided online by the American Congress on Surveying and Mapping under http://www.acsm.net/statecenters.html.

\section{Table 1}

\section{Methods}

All univariate results are age standardized. Let $p_{j}(x)$ be the proportion of deaths at age $x$ in group $j$ and $p(x)$ be the respective proportion in the standard population which is the total black and white US population between ages 50 and 100. Each age in group $\mathrm{j}$ is re-weighted such by $W_{i}(x)=\frac{p(x)}{p_{j}(x)}$, that for each combination of education, race and region the same mean age at death is derived. The marital status is age-adjusted by reweighting the death records such that the mean age at death is the same for each category of marital status. 
We use Eq.1 to estimate the simultaneous effects of the characteristics of the decedents on their age at death

$$
x_{j}=\alpha_{0}+\beta^{\prime} Y_{j}+\gamma^{\prime} I_{j}+u_{j} .
$$

Let $x_{j}$ be age at death, $Y_{j}$ the matrix of the indicator variables sex, education, race, region and marital status, and $I_{j}$ the matrix of the two-way interactions between the variables; $\alpha_{0}$, $\beta$, and $\gamma$ are the parameter estimates. The error term $u_{j}$ follows a normal distribution with mean zero and variance $\sigma^{2}$. The above model assumes that the observed data stem from normal distributions with equal variances but with different means. Our descriptive analyses show that the distribution of age at death deviates significantly from a normal distribution and that the variances of the different categories are not homogenous. The differences in the variances are small, however, and mainly significant because of the large numbers of observations. We tested the sensitivity of the model to the violation of the model assumptions by using different starting ages, and by using log and rank transformations of age. We found that the results were largely insensitive to these changes and we concluded that our model is robust and that the results are not influenced by the violations of the model assumptions.

\section{Results}

We find a highly significant difference in mean age at death by month of birth for US decedents who died between 1989 and 1997. Those born in June and July die about 0.44 of a year earlier than the October-born. The difference is slightly larger for males $(0.434$ of a year) than for females ( 0.402 of a year).

\section{Latitude and Temperature}

We do not find a positive correlation between the peak-to-trough difference in the mean age at death and the latitude, on the contrary, we find a small but significant negative correlation (Spearman correlation=-0.308, $\mathrm{p}=.033$ ). The correlation of the month-of-birth effect with the maximum difference in temperature, another indicator for 
latitude, is also negative and significant (Spearman correlation=-0.293, p=.048). We find a small positive correlation between the peak-to-trough difference in mean age at death and both, maximum (Spearman correlation=0.281, p=.059) and minimum temperature (Spearman correlation $=0.326, \mathrm{p}=.027$ ). When we divide causes of death into cancer mortality, mortality from cardiovascular disease, mortality from other natural and nonnatural diseases, we find that the already low correlation results mostly from mortality related to cardiovascular disease (unpublished). Figure 1 shows the scatterplots of the peak-to-trough differences in mean age at death by month of birth and the four variables.

Figure 1 here.

\section{Education}

Comparing the two educational groups we find that the mean age at death of those with a basic education is 78.35 years, while it is 75.43 years for people with a high education. This is contrary to the evidence from a large body of literature stemming from research over the last three decades, which proves that the lower educated have shorter life spans than the higher educated (Kitagawa \& Hauser 1973, Valkonen 1989, Elo \& Preston 1996). In the cross sectional death data the mortality advantage of the lower educated is due to a change in the educational distribution over time. The oldest decedents are more likely to have received basic education than those who died in their $60 \mathrm{~s}$ or $70 \mathrm{~s}$

Figure 2 shows that the age standardized differences in lifespan by month of birth vary significantly $(\mathrm{p}<.0001)$ according to education levels. The difference between the spring trough and the winter peak is 0.62 of a year $(\mathrm{p}$-value $<.0001)$ for those with a low education and 0.38 of a year for the highly educated ( $\mathrm{p}$-value <.0001).

Figure 2 here

Race

The month-of-birth pattern of the 1.7 million blacks with a mean age at death of 73.2 years differs significantly $(\mathrm{p}<.0001)$ from that of the 13.9 million whites who died at 
an average age of 77.03 years (Figure 3 ). The pattern for whites reveals the familiar features: a sinusoidal curve with a June trough and a September peak. The agestandardized difference between the two months is 0.49 of a year and is highly significant $(\mathrm{p}<.0001)$. The pattern for the black decedents, however, differs not only with respect to the number of years between the trough and the peak $(0.57$ of a year, $p<0.001)$ but also with respect to the shape of the curve. The mean age at death is highest for those born between January and March. As in the case of whites, the mean age at death is lowest for decedents born in July.

Figure 3

\section{Region of birth}

The age standardized peak-to-trough difference in the month-of-birth pattern increases from the North to the South. The difference is smallest in New England with 0.31 of a year and largest in the East South Central Region with 0.86 of a year (Table 2). The differences in the West are intermediate. The pattern is similar in all regions with a trough in June/July and a peak in September/October. Some regions reveal a secondary peak in the first three months of the year (Pacific, West South Central).

Table 2 here

Region of birth, education and race are highly confounded, therefore we explore the differences in the month-of-birth pattern by education and by race. We find that the regional differences are neither due to differences in education (Figure 4) nor to differences in race (Figure 5).

We find highly significant racial differences $(p<.0001)$ in the month-of-birth pattern stemming solely from the South. In the North the pattern does not differ by race. In the South the pattern for whites follows a sinusoidal curve with a peak in October and a trough in June/July. The curve for blacks has its major peak in the first three months of the year and its trough in June/July. Contrary to whites, those born in fall do not experience a major mortality advantage later in life. 
The two educational groups follow the same sinusoidal pattern in all regions and the difference between the trough and the peak is generally larger among the poorly educated than among the highly educated. Particularly striking and highly significant is the difference between the educational groups in the East and West North Central regions and in the East and West South Central regions. For both educational groups the regional differences in the month-of-birth pattern increase significantly from the North to the South.

Figure 4 and Figure 5 here.

\section{Marital Status}

We find highly significant differences $(\mathrm{p}<.0001)$ in the month-of-birth pattern by marital status. As expected, the age standardized difference between the peak and the trough is largest for the never-married ( 0.62 of a year, $\mathrm{p}<.0001)$, and smallest for the married $(0.40$ of a year, $\mathrm{p}<.0001)$; the widowed $(0.45, \mathrm{p}<0.0001)$ and the divorced $(0.44$, $\mathrm{p}<0.0001)$ are intermediate.

Figure 6 here

The differences in the month-of-birth pattern depend on education, race, marital status, and region of birth. In our multivariate analysis of the ages at death, the main effects of sex, month of birth, education, race, region of birth, marital status and all the two-way interactions of the variables are highly significant at $p<.0001$. Overall the model explains 25 percent of the variation in ages at death. About 86 percent of the model explanation is due to the effect of marital status and only 0.4 percent, to the effect of month of birth. The large majority (70\%) of the 0.4 percent result from the interactions of month of birth with region of birth and race (Table 3 ).

Table 3 here 


\section{Causes of death}

Since US death records contain more then 15 million decedents we are able to verify the month-of-birth pattern for the same causes of death which we analyzed in our study of Austrian mortality (Doblhammer \& Vaupel 2001). We generally confirm the month-of-birth patterns for Austria. Those causes of death that were of borderline significance or insignificant in the Austrian study are generally significant in the US data set (e.g. lung cancer, diabetes mellitus).

In the following we will present the results for different causes of death and relate the findings to existing research. Some literature exists about the relationship between month of birth and the incidence of malignant neoplasms. Extensive research has been done on nervous and mental disorders. Hardly any studies exist about the relationship of month of birth and circulatory disease. However, there is convincing evidence that the causal mechanisms of circulatory diseases are linked to the environment in-utero or in early infancy.

Table 4 here

\section{Cancer}

We find highly significant differences $(\mathrm{p}<=0.001)$ in mean age at death by month of birth for breast cancer, prostate cancer, lung cancer, colorectal cancer and the residual group of other cancers. Differences are significant at $\mathrm{p}=0.05$ for stomach cancer, pancreatic cancer and liver cancer, and not significant $(p>0.05)$ for uterus cancer. None of the cancers reveal differences by sex or educational status (Table 4, Figure 7).

Lung cancer is the only malignant neoplasm with significant differences by marital status (Figure 8), race and region (Figure 9). The differences in mean age at death are largest among the never married, but they follow a different pattern for blacks and whites. Similar to total mortality, mean age at death for blacks peaks among the Marchborn and does not reveal a fall peak as in the case of whites. Contrary to total mortality there is no North-South trend in the magnitude of the difference. Differences are smallest in the Middle Atlantic region, and seem to be largest in the Mountain region. However, 
not only the magnitude changes between the regions but also the shape of the curve, with the East South Central region revealing a particularly distinct pattern.

Figures 7,8,9 here

These results are consistent with the results of Jansson and Malahy (1981), which are based on the Third National Cancer Survey of the United States that consisted of about 180,000 patients. They find that patients born between January and April are diagnosed with cancer 1-1.5 years later and live one year longer than do patients born in June to August. They do not find differences in the season-of-birth distributions of cancer patients for males and females. They find differences in the month-of-birth distribution for different sites of the lesions: colon, rectum and breast cancer patients have an almost identical distribution, while stomach and lung cancer patients have significantly different season-of-birth distributions. The authors attribute this to differences in the geographic distributions and to social differences.

When Jansson and Malahy compared the maximum difference between the monthly temperature at a place and the maximum difference between monthly frequencies of birth among cancer patients they find a positive correlation of $r=0.89$. This is different to our finding that only a small correlation exists between the maximum mean age at death by month of birth and temperature variables. Jansons and Malahy's approach, however, confines monthly differences in the seasonal distribution of the number of births with the month-of-birth effect on life span. The high correlation, thus, is most probably the result of the correlation between the seasonal distribution of births and temperature, which, among others, has been demonstrated by Lam and Miron (1996). The authors conclude that the relationship between month of birth and cancer probably reflects general differences in the health status of persons born at different times of the year rather than being related to the etiology of cancer.

A Swedish study compares the birth distribution of 115,670 women with breast cancer to the total number of live births by month of birth from 1858 to 1968 (Yuen et al. 1994). Month of birth was a significant risk factor for breast cancer, but not for cancers of the other sites (440,948 women). For the older birth cohorts (1880-1920) they find an 
increased risk for women born in May and June. The pattern for women born after 1950, however, was completely different with a maximum in autumn. As age and cohort is confounded in their analysis these women were a maximum of 39 years old and thus, represent pre-menopausal breast cancer, whose etiology may differ from breast cancer of post-menopausal women. They discuss theories of seasonal fluctuations in pregnancy estrogen, other pregnancy hormones or post-natal exposures like diet. They also mention seasonal differences in birth weight as a risk for breast cancer.

A Japanese study (Hu et al. 1996) did not find differences in the breast cancer risk according to the month of birth of 81,162 women who died of breast cancer.

\section{Diseases of the Circulatory System}

Our findings show that the differences in lifespan by month of birth largely result from circulatory diseases (Table 4). Acute myocardial infarctions, ischemic heart disease, cerebrovascular disease, the residual group of other heart diseases, as well as the causes of death related to circulatory diseases like accidental falls, diabetes mellitus (ICD9 250), and pneumonia and influenza show a distinct month-of-birth pattern (Fig. 10). Those born in spring die earlier than those born in fall. There are no differences by sex, but highly significant differences by race. Among blacks the peak in mean age at death is shifted to the first three months of the year. In addition to the differences by race, highly significant differences by marital status exist, with the never married who were born in May and June particularly disadvantaged. In addition, highly significant regional differences do exist and the month-of-birth effect is strongest in the East South Central and the West South Central region.

Most research that explores the effect of early life circumstances on late life health and mortality focuses on circulatory diseases (for reviews see Elo and Preston 1992, Kuh \& Davey Smith 1993; Barker 1994, Barker 1995, Davey Smith et al. 1997, Davey Smith et al. 2000). Surprisingly, we found only two studies on how these diseases are related to month of birth. They both explore the relationship between month of birth and cerebral hemorrhage. Caroll \& Haddon (1964) included deaths under age 34 and did not find a relationship. Nonaka \& Imaizumi (2000) studied subarachnaoid hemorrhage (ICD9 code 430) in Japan by comparing the month-of-birth distribution on death records 
from the years 1986-1994 with the monthly distribution of births for the years 1900-1959. They found an excess risk of $8-23$ percent for the June- to September-born. More attention has been paid to diseases that are considered as a risk factor for circulatory diseases, in particular insulin dependent diabetes. There are twelve recent studies (Block et al. 1994, Dahlquist \& Kaellen 1996, Fichera et al. 2001, Jongbloet et al. 1998, Kida et al. 2000, Laron et al. 1999, Neu et al. 2000, Rothwell et all 1999, Samuelsson et al. 1999, Songini et al. 2001, Ursic-Bratina et al. 2001, Chen et al. 1998) that are concerned with the influence of month of birth on insulin dependent diabetes in children. With the exception of Chen et al., all these studies find a significant relationship between month of birth and the incidence of Diabetes I. The authors of the studies primarily attribute the relationship to intrauterine infections or infections early in infancy, although the exact mechanism is still unknown.

Figure 10 here

\section{Diseases of the Respiratory System and Infectious disease}

We find a highly significant month-of-birth effect for chronic diseases of the respiratory system and for pneumonia and influenza (Table 4, Figure 11). The effect differs by region and race and in the case of chronic respiratory diseases also by marital status. Considerable evidence exists that lower respiratory tract infections early in life lead to chronic obstructive lung disease late in life (for a review see Elo and Preston 1992). In young children, viruses are the principal etiological agents that cause lower respiratory tract infections. Elo and Preston point out that since the lungs of children undergo developmental changes it is plausible that clinically severe infections could have lasting effects.

In addition to respiratory tract infections in childhood, an association between asthma and the height has been documented (Norjavaara 2001). Since shorter adults have a greater risk of death (Waaler 1984, Floud et al. 1990, Fogel 1994) this is indirect evidence on the effect of respiratory symptoms in childhood on adult health. In addition, a large body of literature exists, which shows a significant relationship between monthof-birth and allergies in childhood. A study of Queensland, Australia, shows that school 
children who experience frequent wheezing (one or more episodes per month) are $60 \%$ more likely to be born in spring or summer (Duffy 1991). In Hong Kong the prevalence of wheezing is highest for girls born in January/February and lowest for those born in July/August (Lau and Karlberg 1998). A study based on British school children and middle aged adults found that admission for bronchiolitis in the first year of life was three times more common among children born from September to November than those born from March to May. Admissions for asthma were significantly more common among children and young adults born in autumn. Among adults however, those born in autumn had a higher forced ventilatory capacity and there was little variation in hospital admissions for chronic bronchitis/emphysema and pneumonia (Strachan et al. 1994). The authors concluded that there was no evidence in their study for a causal link between chest illness in infancy and later development of chronic bronchitis and emphysema.

Significant differences in the month-of-birth effect do also exist for mortality from infectious diseases. A recent study of the relationship between month of birth and mortality in The Gambia found that those born shortly after the hunger season had a higher risk of dying before their $45^{\text {th }}$ birthday (Moore 1997). All the deaths were caused by either pregnancy related deaths or by infectious disease. The authors conclude that malnutrition together with a high energy expenditure of mothers in their last trimester of pregnancy affected the immune systems of their babies.

Figure 11 here

\section{Diseases of the nervous and mental system}

Most of the research about the relationship between month of birth and the incidence of diseases has been conducted for mental disorders, in particular schizophrenia and other bipolar disorders (for reviews see Torrey et al. 1997, Fossey \& Shapiro 1992, Bradbury \& Miller 1985). Torrey et al. review more than 250 studies, covering 29 Northern and five Southern Hemisphere countries, and find a remarkable consistency in the results. There is a 5-8 percent winter/spring excess of births for both schizophrenia and mania/bipolar disorders. The season-of-birth effect has also been studied for autistic disorder (Barak et al. 1995, Bolton et al. 1992, Ticher et al. 1996), Alzheimer patients 
(Philpot et al. 1989, Dysken et al. 1991, Henderon et al. 1991, Vitiello et al 1991, Vezina et al. 1996), and for anorexia nervosa patients (Nielsen 1992, Rezaul et al. 1996, Eagles et al. 2001). With the exception of a few studies, they all find significant differences in the birth distribution of the patients as compared to the general population or the control group. For diseases of the nervous system significant differences by month of birth have been shown for Parkinson's disease (Miura et al. 1987, Mattock et al. 1988), multiple sclerosis (Miura et al. 1987, Rothwell et al. 1999, Sadovnick et al. 1994, Salemi et al. 2000, Wiberg et al. 1994) and epilepsy (Procopio \& Marriott 1998).

Our results confirm the findings of all these studies (Table 4, Fig. 12) with the exception of multiple sclerosis, where we do not find a significant month-of-birth effect. As we observe only 12,038 deaths from multiple sclerosis, the absence of a significant pattern may be attributable to the small number of observations.

Figure 12 here

\section{Non-natural causes of death.}

We find significant differences in mean age at death by month of birth for suicides, car accidents, and for the residual group of all other non-natural causes of death (Table 5, Fig. 11). Those born in spring experience a higher risk than those born in fall. Considering the large number of deaths that fall into each of these groups the month-of birth-effect is only of borderline significance.

The evidence about a month-of-birth effect for suicide is mixed. A recent study on Alaska natives showed more suicides among summer births (Kettl et al. 1997). Likewise, Pokorny (1960) found an overrepresentation of suicide cases among July-born. Three other studies could not find a relationship (Lester 1987, Lester et al. 1970, Sanborn \& Sanborn 1974). Although, at a first glance, the relationship between month of birth and the risk of suicide may be surprising, plausible explanations exist. Suicide at old age is often related to chronic disease which, according to our results, is significantly influenced by the month of birth. Chotai et al. (1999) report differences in suicide methods according to month of birth. Those who preferred hanging rather than poisoning or petrol gases were significantly more likely to be born in February to April than 
October to January, particularly among males aged 45 or younger. The suicide attempts may thus be independent of the month of birth. Those born in late winter/early spring, however, may use suicide methods that lead to death more often than those born in fall. This leads to research about the effect of month of birth on personality which, due to its extensive nature, is beyond the scope of this paper.

Differences in mean age at death by month of birth for car accidents may be explained by the month-of-birth pattern for alcoholism that has been demonstrated repeatedly (Goldberg \& Newlin 2000, Modestin et al. 1995, Levine \& Wojcik 1999, London 1998, Kunugi et al. 1998, Lang 1931) although two other studies did not find a pattern (Dalen 1975, Watson et al. 1984)

Table 5 here

\section{Discussion and Conclusion}

We find a significant maximum difference of 0.44 of a year in mean age at death by month of birth on the basis of 15 million death certificates for the United States. This difference is comparable to the differences we found for Austria (0.6 of a year), Denmark ( 0.3 of a year) and Australia ( 0.6 of a year) but it is much smaller than the 2.6 years that was recently published for Kiev (Vaiserman 2002). The pattern of the differences resembles those of Austria and Denmark.

The differences depend on race, region of birth, marital status, and education. They are larger for the less educated, for the never married, for blacks, and they increase from the North to the South. This increase is not caused by differences in the educational or racial composition of the decedents but is independent of these characteristics. The peak-to-trough difference in lifespan is slightly larger for African-Americans than for whites and their pattern follows a different curve. This difference in the pattern, however, is only visible in the South.

The month-of-birth effect is largest among the never married, which supports our view that the month of birth is related to the frailty of the population. There has been 
ample research to show that there is a health selection into marriage (Lillard \& Panis 1996) and that the never married experience higher mortality (Goldman \& Hu 1993).

We find a negative correlation between the maximum differences in the monthof-birth pattern and the latitude of state of birth. This permits us to rule out the hypothesis that the differences are related to the seasonality in the duration of sunshine through its effect on neuroendocrine functions. To accept this hypothesis a positive correlation would have been necessary.

The trough in life expectancy for those born in June and July rather than in April and May lets us reject the hypothesis that high temperature at the time of conception is the responsible factor. Those born in June and July were conceived in September and October, which is between one and three months after the period of maximum temperatures (July and August).

The rejection of the two hypotheses is consistent with the outcome of a review of more than 250 studies about schizophrenia and bipolar disorder (Torrey et al. 1997). The studies that tested the existence of a correlation between latitude and the month-of-birth effect came to mixed conclusions: some suggested the existence of a latitude gradient (Dalen 1975, Torrey 1977) while others did not (Torrey et al. 1991). McNeil et al. (1975) was unable to find a correlation between summer temperatures at the time of conception and winter births of individuals with schizophrenia. Hare and Moran (1981) and Watson et al. (1984) did not find a correlation between summer temperatures and winter births.

The regional differences in the month-of-birth pattern are consistent with the hypothesis that nutrition and infectious disease in utero or in the first year of life are the causal mechanisms. We found that the amplitude of the month-of-birth pattern was largest in the South, which is the part of the US where diet, particularly in rural areas, was deficient throughout the year and where malnutrition was common in winter and early spring. It is also the part of the US with the highest incidence of infectious diseases, particularly of the gastro-intestinal tract, due to the hot and humid climate.

We find that circulatory disease, cancers, and other natural causes of death like chronic obstructive lung disease reveal a strong month-of-birth pattern. This suggests that there is not one causal mechanism, but that both nutrition and infectious disease are important factors. Heart disease has primarily been linked to fetal development and 
nutrition during pregnancy. Chronic obstructive lung disease was linked to lower respiratory tract infection during infancy and childhood, which in children are mainly caused by viruses. Other diseases in which a major role for persistent viruses has been suggested include multiple sclerosis, Parkinson's disease, juvenile diabetes, and presenile dementia (Elo and Preston 1992). Resent research suggests a relationship between Helicobacter pylori infections in childhood and stomach cancer (Elo and Preston 1992). Our results are consistent with all these studies.

The multivariate model of age at death shows that educational differentials in the month-of-birth pattern are small compared to racial or regional differences. This result is reminiscent of the finding by Preston and Haines that the three single most important factors that explain most of the variance in US child mortality were race, size of the birthplace and region (Preston \& Haines 1991). We conjecture that the factors that are mainly responsible for infant mortality in general are also the factors that cause the differences in lifespan by month of birth. The contemporary view at the beginning of the $20^{\text {th }}$ century was that the mother's health status and whether the mothers breastfed their babies were two factors - in addition to housing, sanitation and general poverty - that were closely linked with the survival of infants. In other words, infant mortality was largely determined by the nutrition and health of the mother and by breastfeeding, which helped prevent infectious disease in the first months of life.

In our analysis, the size of the birthplace is missing, which may explain the puzzling finding that the month-of-birth pattern among African-Americans is not much larger than among the white population. African Americans, particularly in the South, were mainly living in rural areas where life circumstances were healthier than in urban areas. Among the childhood conditions that predicted survival to advanced ages among African Americans, the factors that were found to be most predictive were having a farm background, literate parents, and living in a two-parent household (Preston, Hill \& Drevenstedt 1998). In other words, correcting for the size of the place of birth may significantly increase the month-of birth effect for African-Americans.

The difference between urban and rural environment may also account for the finding that the pattern differs between blacks and whites in the South of the US. One explanation is that the hard farm-work in the second part of the year prevents African- 
American infants born in fall from experiencing mortality advantages similar to that of the white population. Peak growth in-utero is during the third trimester. For infants born in fall, the peak growth coincides with a period of heavy work and therefore of high energy expenditures from their pregnant mothers. Evidence from The Gambias show that the high energy expenditure and low energy intake of pregnant mothers during the last trimester result in a peak-to-trough difference in birth weight of approximately 200-300g (Moore 1998) and in a significant difference in survival to age 45 by month of birth (Moore et. al 1997). A heavy workload on the fields would also prevent mothers from breastfeeding their infants and would expose the infants to a higher risk of infectious disease.

Our results provide unambiguous evidence that the earliest years influence adult health and mortality and that this influence is independent of the accumulated effects of deprivation over the whole life course. The challenge for future research is to more systematically test how the interaction of seasonal differences in nutrition and seasonal differences in disease affect adult health and survival.

\section{Acknowledgements}

Research was supported by the Max Planck Institute for Demographic Research. The author feels indebted for the support and comments of James W. Vaupel and the help of Omer Gersten in the analysis of causes of death. The present version of the article was prepared for the Annual Meeting of the Population Association of America, Atlanta, USA, 9-11 May 2002. 


\section{References}

Barak, Y., Ring, A., Sulkes, J., Gabbay, U., and Elizur, A. 1995. Season of birth and autistic disorder in Israel . American Journal of Psychiatry 152(5):798-800.

Barker, D.J.P.1994. Mothers, babies and diseases in later life (London: BMJ Publishing Group).

Barker, D.J.P. 1995. Fetal origins of coronary heart disease. BMJ 311, 171-174

Ben-Shlomo, Y. Davey Smith, G. 1991. Deprivation in infancy or in adult life: which is more important for mortality risk? Lancet 337(8740):530-4.

Block, T.; Pedersen, C. R.; Volund, A.; Pallesen. C., and Buschard, K. 1994. Perinatal determinants among children who later develop IDDM. Diabetis Care 17:1154-1157.

Bolton, P., Pickles, A., Harrington, R., Mcdonald, H, and Rutter, M. 1992. Season of birth: issues approaches and findings for autism. Journal of Child Psychological Psychiatry 33:509-530.

Bradbury, J. H. and Miller, G. A. 1985. Season of birth in schizophrenia: a review of evidence, methodology, and etiology. Psychological Bulletin 98:569-594.

Carroll, R. E. and Haddon, W. jr. 1964. Birth characteristics of persons dying of cerebral aneurysms. Journal of Chronic Diseases 17:705-711.

Centola G., \& Eberley S., 1999. Seasonal variations and age-related changes in human sperm count, motility, motion parameters, morphology, and white blood cell concentration. Fertility and Sterility 72:803-808

Clark R. 1993. Water: The International Crisis. Cambridge: MIT Press.

Colwell R.R. 1996. Global climate and infectious disease: the cholera paradigm. Science 274:2025-31.

Chotai, J., Salander Renberg, E., and Jacobsson, L. 1999. Season of birth associated with the age and method of suicide. Archive of Suicide Research 5:245-254.

Dahlquist, G. G. and Källen, B. A. J. 1996. Time-spacing clustering of date birth in childhood-onset diabetis. Diabetis Care 19:328-332. 
Dalen, P. 1975. Season of birth: A study of Schizophrenia and other mental disorders. Amsterdam.

Davey Smith, G., Harding, S. \& Rosato ,M. 2000. Relation between infant's birth weight and mothers' mortality: prospective observational study. Brit Med J 320, 839-840.

Davey Smith, G., Hart, C., Ferrell, C., et al. 1997. Birth weight of offspring and mortality in the Renfrew and Paisley study: prospective observational study. Brit Med J 315, 1189-1193.

Dirks, R.T., \& Duran, N. 2001. African American dietary patterns at the beginning of the $20^{\text {th }}$ century, Journal of Nutrition 131 (7): 1881-1889.

Doblhammer G., \& Vaupel J.W. 2001. Lifespan depends on month of birth. Proceedings of the National Academy of Sciences of the United States of America, 98:5, 2934-2939.

Duffy, D. L. and Mitchell, C. A. 1991. Respiratory symptoms in Queensland and Australia schoolchildren - an association between month of birth and respiratory illness. Clinical \& Experimental Allergy 21(2):231-234.

Dyson L.K. 2000. American Cuisine in the $20^{\text {th }}$ Century, FoodReview 23(1),2-7.

Eagles, J. M., Andrew, J. E., Johnston, M. I., Easton, E. A., and Millar, H. R. 2001. Season of birth in females with Anorexia nervosa in Northeast Scotland. The International Journal of Eating Disorders 30(2):167-175.

Elo, I.T. \& Preston, S.H. 1992. Effects if Early-Life conditions on adult mortality: a review. Population Index 58(2):186-212.

Elo IT \& Preston S.H. 1996. Educational differentials in mortality: United States, 1979-85. Social Science\& Medicine, 42(1):47-57

Fichera, G.; Arpi, M. L. Squatrito S.; Purello, F; Ashkenazi, I., and Laron, Z. 2001. Seasonality of birth in children (0-14 years) with diabetis mellitus type 1 in the District of Catania. The Journal of Pediatric Endocrinology \& Metabolism14:95-96. 
Floud, R., Wachter K. \& Gregory A. 1990. Height, health and history (Cambridge: Cambridge University Press).

Fogel, R.W. 1994. Economic growth, population theory, and physiology: the bearing of long-term processes on the making of economic policy. Am Econ Rev 84, 369-395.

Fossey, E. and Shapiro, C. M. 1992. Seasonality in psychiatry - A review. Canadian Journal Psychaiatry 37:299-308.

Fuller Torrey, E., Miller, J., Rawlings, R., and Yolken, R. H. 1997. Seasonality of births in schizophrenia and bipolar disorders: a review of the literature. Schizophrenia Research 28(1):1-38.

Goldberg, A. E., Newlin, D. B. 2000. Season of birth and substance abuse: Findings from a large national sample. Alcoholism: Clinical and Enviromental Research 24(6):774-780.

Goldman, N., Lord, G., Hu, Y. 1993. Marriage selection and age patterns of mortality: a mathematical investigation. Mathematical Population Studies 4(1): 51-73.

Goldman, N., Hu, Y. 1993. Excess mortality among the unmarried: a case study of Japan. Social Science and Medicine 36(4): 533-59

Gueri , M., Gonzalea, C., and Morin V. 1986. The effect of the floods caused by 'El Nino' on health. Disasters 10: 118-124.

Hare, E., Moran, P. 1981. A relation between seasonal temperature and the birth rate of schizophrenic patients. Acta Psychiatr. Scand. 63, 396-405.

Henderson, A. S., Korten, A. E., Jorm, A. F., McCusker, E., Creasy, H., and Broe, G. A. 1991. Season of birth in Alzheimer's disease in the Southern hemisphere. Psychological Medicine 21:371-374.

Hu, Y. H.; Kurioshi, T.; Matsushita; Y.; Nagata, C., and Shimizu, H. 1996. Birth season and breast cancer risk in Japan. Breast Cancer Research \& Treatment 39( 3):315-319

Huntington, E. (1938) Season of birth (New York: J. Wiley \& Sons, Inc.)

Jansson, B. and Malahy, M. A. 1981. Cancer risk, Age at diagnosis, and Age at death as functions of season of birth. Cancer Detection and Prevention 4:291-194. 
Jongbloet P.H. 1975. The effects of pre-ovulatory overripness of human eggs on development. In Blandau, R.J. (ed.), Aging Gametes, S. Karger. Basel, Switzerland, 300-329.

Jongbloet, P. H.; Greonewould, H. M. M., and Hirasing, R. A. Vaan Buuren S. 1998. Seasonality of birth in patients with childhood diabetis in the Netherlands. Diabetis Care 21:190-191.

Kida, K., Mimura, G.; Ito, T., Murakami, K., Ashkenazi, I.; Laron, Z. 2000. Incidence of type 1 diabetis (IDDM) in children (0-14 years) in Japan (1986-1990) including an analysis for seasonality of onset and month of birth. Diabetic Medicine 17:59-63.

Karl, T.R. \& Koss W.J., 1984: "Regional and National Monthly, Seasonal, and Annual Temperature Weighted by Area, 1895-1983." Historical Climatology Series 4-3, National Climatic Data Center, Asheville, NC, 38 pp.

Kettl, P. A. Collins T. Sredy M. \& Bixle E. O. 1997. Seasonal differences in suicide birth rates in Alaska Natives compared to other populations. American Indian and Alaska Native Mental Health Research 8:1-10.

Kitagawa EM \& Hauser PM 1973. Differential Mortality in the United States: A study in socioeconomic epidemiology. Cambridge, MA: Harvard University Press.

Köppen, W. 1936: Das geographische System der Klimate. In: KÖPPEN, W., u. R. GEIGER: Handbuch der Klimatologie. Band 1, Teil C. Berlin.

Korlath JA, Osterholm MT, Judy LA, Forfang JC, Robinson RA. 1985. A point-source outbreak of campylobacteriosis associated with consumption of raw milk. J Infect Dis 152:592-6.

Kuh, D. \& Davey Smith, G. 1993. When is mortality risk determined? Historical insights into a current debate. Social History of Medicine 6(1), 101-123.

Kunugi, H., Watanabe, H., Sekiba, K., and Kazamatsuri, H.1998. Season of birth of chronic alcoholics. Journal of Psychiatric Research 32:321-323.

Laron, Z., Shamis, I., Nitzan-Kaluski, D., and Ashkenazi, I. Month of birth and subsequent developmentof type 1 diabetis (IDDM). 1999. The Journal of Pediatric Endocrinology \& Metabolism 12:397-402. 
Lam, D.A. \& Miron, J.A. 1996. The effects of temperature on human fertility. Demography 33, 291306.

Lau, Y. I. and Karlberg, J. 1998. Prevalence and risk factors of childhood asthma, rhinitis and eczema in Hong. J Paediatr Child H 34(1):47-52.

Lillard L.A. \& Panis C.W.A. 1996. Marital Status and Mortality: The Role of Health (in Mortality), Demography 33(3): 313-327.

Levenstein, H. 1993. Paradox of Plenty: a Social History of Eating in Modern America. New York. Oxford, University Press.

Levenstein, H. 1988. Revolution at the Table: The transformation of the American Diet. New York, Oxford, University Press.

Lester, D. 1987. Month of birth of suicides, homicides and natural deaths. Psychological Reports 60: 1310.

Lester, D., Reeve, C. L., and Priebe, K. 1970. Completed suicide and month of birth. Psychological Reports 27:210.

Levine, M. E. and Wojcik, B. E. 1999. Alcoholic typology and season of birth. Journal of Addictive Disorders 18:41-52.

London, W. P. 1998. Alcoholism: Theoretical consideration of season of birth and geographic latitude. Alcohol. 4:127-129.

Madico, G., McDonald J., Gilman R.H., Cabrera, L., Sterling, C.R. 1997. Epidemiology and treatment of Cyclospora cayetanenis infection in Perucian children. Clin. Infect. Dis. 24:977-981.

Mattock, C., Marmot, M., and Stern, G. 1988. Could Parkinson’s disease follow intra-uterine influenza? A speculative hypothesis. Journal of Neurology, Neurosurgery and Psychiatry 35:753-756.

McNeil, T., Dalen, P., Dzierzykray-Rogalska, M., Kaij, L., 1975. Birth rates of schizophrenics following relatively warm versus relatively cool summers. Arch Psychiatr. Nervenkr. 221,1-10. 
Miura, T., Shimura, M., and Kimura, T. 1987. Season of birth in parkinsonism. In Miura T. (ed) Seasonality of birth: Progress in biometeorology . Hague, Netherlands. 157-162.

Modestin, J., Ammann, R., and Wurmle, O. 1995. Season of birth: Comparison of patients with schizophrenia, affective disorders, and alcoholism. Acta Psychatrica Scandinavia 91:140-143.

Moore, S.E., Cole, T.J., Poskitt EME, Sonko, B.J., Whitehead R.G., McGregor I.A. \& Prentice A.M. 1997. Season of birth predicts mortality in rural Gambia. Nature 338,434.

Moore S.E. 1998. Nutrition, immunity and the fetal and infant origins of disease hypothesis in developing countries. Proceedings of the Nutrition Society 57, 241-247.

Morgan, R., 1978. Seasonality in Schizophrenia (letter). Lancet, 830.

Neu, A., Kehrer, M., Ashkenazi, I., and Laron, Z. 2000. Seasonality of birth in children (0-14 years) with diabetis mellitus type 1 in Baden-Württemberg, Germany. The Journal of Pediatric Endocrinology \& Metabolism 13:1081-1085.

Nielsen, S. 1992. Seasonal variation in anorexia nervosa? Some preliminary findings from a neglected area of research. The International Journal of Eating Disorders 11:25-35.

Nonaka, K. and Imaizumi, Y. 200x. Deaths from cerebrovascular diseases correlated to month of birth: elevated risk of death from subarachnoid hemorrhage among summer born. International Journal of Biometeorology 44:182-185.

Norjavaara E, de Verdier MG, Lindmark B. 2001. Adult height in women with childhood asthma - a population-based study. PHARMACOEPIDEM DR S 10 (2): 121-125.

Pallast, E.G.M., Jongbloet, P.H., Straatman, H.M., Zielhuis, G.A. 1994. Excess seasonality of births among patients with schizophrenia and sesonal ovopathy, Schizophrenia Bull. 129, 355-361.

Pasamanick, B., 1986. Seasonality of schizophrenia births (letter) Am. J. of Orthopsychiatry 56, 168169.

Philpot, M., Rottenstein, M., and Burns, A. 1989. Season of birth in Alzheimer's disease . The British Journal of Psychiatry 155:662-666. 
Pokorny, A. D. 1960. Characteristics of 44 patients who subsequently committed suicide. Archives of General Psychiatry2 :314-323.

Preston, S.H. \& Haines, M.R. 1991 Fatal years. Child mortality in late nineteenth-century in America (Princton University Press, Princton).

Quested, D.J. 1991. Incidence rates of schizophrenia (letter). Br. J. Psychiatry 159, 587-588.

Preston, S.H., Hill, M.E., Drevenstedt, G.L. 1998. Childhood conditions that predict survival to advanced ages among African Americans. Social Science and Medicine 47 (9):1231-1246.

Procopio, M. and Marriott, P. K. 1998. Seasonality of birth in epilepsy: A danish study. Acta Neurologica Scandinavica 98:297-301.

Rezaul, I., Persaud, R., Takei, N., and Treasure, J. 1996. Season of birth and eating disorders. The International Journal of Eating Disorders 19:53-61.

Rothwell, P. M., Gutnikow, S. A., McKinney, P. A., Schober, E., and Ionescu-Tirgoviste, C. 1999. Seasonality of birth in children with diabetis in Europe: multicentre cohort study. BMJ. 319:887-888.

Samuelsson, U., Johansson, C., and Ludvigsson, J. 1999. Month of birth and risk of developing insulin dependent diabetes in southeast Sweden . Archives of Disease in Childhood 81(2 ):143-146.

Songini, M., Casu, A., Ashkenazi, I., and Laron, Z. 2001. Seasonality of birth in children (0-14 years) and young adults (0-29 years)with type 1 Diabetes Mellitus in Sardinia differs from that in the general population . The Journal of Pediatric Endocrinology \& Metabolism 14(6):781-783.

Samuelsson, U., Johansson, C. \& Ludvigsson, J. 1999. Month of birth and risk of developing insulin dependent diabetes in southeast Sweden Arch Dis Child 81,143-146.

Shears, P. \& Wright, A., 1995. Community-acquired infections among children in an urban environment: a-2-year prospective study in Liverpool, U.K. J Infect 1995 30(2): 173-177.

Strachan, D. P., Seagroatt, V., and Cook, D G. 1994. Chest illness in infancy and chronic respiratory disease in later life: An analysis by month of birth. INT J EPIDEMIOL 23(5):1060-1068. 
Sadovnick, A. D. Yee, I. M. L. 1994. Season of birth in Multiple sclerosis. Acta Neurologica Scandinavia 89:190-191.

Salemi, G., Ragonese, P., Aridon, P., Reggio, A., Nicoletti, A., Buffa, D., Conte, S., and Savettieri, G. 2000. Is season of birth associated with multiple sclerosis? Acta Neurologica Scandinavica 101(6):381-383 .

Shimura, M., Kimura, T., and Miura, T. 1987 Season of birth in some neurological disorders Multiple sclerosis, amyotrphic lateral sclerosis, senole dementia. In Miura, T. (ed.) Seasonality of birth: Progress in biometeorology . Hague, Netherlands. 163-168.

Sanborn, D. E. and Sanborn, C. J.1974. Suicide and month of birth. Psychological Reports 34:950.

Templer DI, Trent NH, Spencer DA, Trent A, Corgiat MD, Mortensen PB, Gorton M 1992. Season of birth in multiple sclerosis. Acta Neurologica Scandinavica 85 (2): 107-109.

Ticher, A., Ring, A., Barak, Y., Elizur, A., and Weizman. A. 1996. Circannual pattern of autistic births: Reanalysis in three ethnic groups. Human Biology 68:585-592.

Torrey, E.F., Miller, J., Rawlings, R. \& Yolken, R.H. 1997. Seasonality of births in schizophrenia and bipolar disorders: a review of the literature. Schizophr Res 28,1-38.

Torrey, E.F., Torrey, B.B., Peterson, M.R. 1977. Seasonality of schizophrenic births in the United States. Arch. Gen. Psychiatry 34: 1065-1070.

Torrey, E.F., Bowler, A.F., Rawlings, R. 1991. An influenza epidemic and the seasonality of schizophrenic births. In: Kurstak, E. (Ed), Psychiatry and Biological Factors. Plenum Medical Book Company, New York:109-116.

Turnquist, K. 1993. Second-trimester markers of fetal size in schizophrenian(letter) Am. J. Psychiatry $150,1571-1572$.

Ursic-Bratina, N., Battelino, T. Krzisnik C., Laron-Kenet, T., Ashkenazi, I., and Laron, Z. 2001. Seasonality of birth in children (0-14 years) with diabetis mellitus type 1 in Slovenia. The Journal of Pediatric Endocrinology \& Metabolism 14:47-52 
Vaiserman, A.M. 2002. Influence of a season of birth on the mortality structure of the Kiev city inhabitants. ??

Valkonen, T. 1989. Adult mortality and level of education: a comparison of six countries. In: Fox J (ed.), Health Inequalities in European Countries. Aldershot: Gower Publishing; 142-162.

Vezina, H, Houde, L., Charbonneau, H., Beaudry, M., Cholette, A., Daoud, N., Mathieu, J., Robitaille, Y., Veilleux, F., and Gauvreau, D. 1996. Season of birth and Alzheimer's disease : a poulation-based study in Saguenay-Lac-St-Jean/Quebec (IMAGE-Project). Psychological Medicine 26(1):143-149.

Vitiello, B., Hill, J. L., Molchan, S. E., Martinez, R. A., Martinson, H. J., and Sunderland, T. 1991. Lack of seasonal variation in the birth of patients with dementia of the Alzheimer's type. Psychiatry Research 39:21-24.

Waaler H.F. 1984. Height, Weight and Mortality - The Norwegian Experience. Acta Med Scand 1\&Suppl 679.

Watson, C. G.,Kucala, T., Tilleskjor, C., and Jacobs, L. 1984. The birth effect in nonschizophrenic psychiatric patients. Journal of Clinical Psychology 40:884-888.

Watson, C.G., Kucala, T., Tilleskjor, C., Jacobs, L. 1984. Schizophrenic birth seasonality in relation to the incidence of infectious diseases and temperature extremes. Arch. Gen. Psychiatry 41, 85-90.

Wehr, T. 1998. Effect of seasonal Changes in Daylength on Human Neuroendocrine Function, Horm Res 49: 118-124.

Wiberg, M. and Templer, D. I. 1994. Season of birth in multiple sclerosis in Sweden: Replication. Journal of Orthomolecular Medicine 9(2):71-74.

Yuen, J.; Ekbom, A.; Trichopoulos, D.; Hsieh, C.-C., and Adami, H.-O. 1994. Season of birth and breast cancer risk in Sweden. Br. J. Psychiatry 70 :564-568.

Ye Chen, R.-G., Ashkenazi, I., and Laron, Z. 1998. Lack of seasonality in childhood IDDM (0,7 -15 years) in Shanghai, China. The Journal of Pediatric Endocrinology \& Metabolism 11:461-464 
Table 1: Number, proportion and mean age at death of the US decedents by region, sex, education, marital status and race.

\begin{tabular}{|c|c|c|c|}
\hline \multirow{2}{*}{$\begin{array}{l}\text { REGION } \\
\text { Region }\end{array}$} & \multirow[t]{2}{*}{ Total } & Mean age at death & \multirow[t]{2}{*}{$\%$} \\
\hline & & & \\
\hline New England & 928,642 & 77.10 & 0.06 \\
\hline Middle Atlantic & $2,950,756$ & 76.83 & 0.19 \\
\hline East North Central & $2,900,962$ & 77.05 & 0.19 \\
\hline West North Central & $1,855,131$ & 78.68 & 0.12 \\
\hline South Atlantic & $2,409,504$ & 75.34 & 0.15 \\
\hline East South Central & $1,666,643$ & 75.93 & 0.11 \\
\hline West South Central & $1,839,805$ & 76.12 & 0.12 \\
\hline Mountain & 448,687 & 76.12 & 0.03 \\
\hline Pacific & 579,369 & 74.87 & 0.04 \\
\hline \multicolumn{4}{|l|}{ Sex } \\
\hline Males & $7,665,738$ & 74.27 & 0.49 \\
\hline Females & $7,931,214$ & 78.86 & 0.51 \\
\hline \multicolumn{4}{|l|}{ Race } \\
\hline Whites & $13,871,496$ & 77.03 & 0.89 \\
\hline Blacks & $1,725,456$ & 73.20 & 0.11 \\
\hline \multicolumn{4}{|l|}{ Education } \\
\hline Low (<12 years) & $5,261,840$ & 78.35 & 0.34 \\
\hline $\operatorname{high}(>=12$ years $)$ & $8,164,552$ & 75.43 & 0.52 \\
\hline Unknown & $2,170,560$ & 76.80 & 0.14 \\
\hline \multicolumn{4}{|l|}{ Marrital status } \\
\hline Never married & $1,046,611$ & 75.15 & 0.07 \\
\hline Married & $6,844,464$ & 72.77 & 0.44 \\
\hline Widowed & $6,367,655$ & 82.42 & 0.41 \\
\hline Divorced & $1,305,106$ & 69.60 & 0.08 \\
\hline Unknown & 33,116 & 72.80 & 0.00 \\
\hline TOTAL & $15,596,952$ & 76.60 & 100.00 \\
\hline
\end{tabular}


Table 2: Peak-to-trough difference in mean age at death of decedents born in a specific month by race, education and birth region.

Age standardized difference in years

\begin{tabular}{cccccc}
\hline \multicolumn{2}{c}{ US total } & \multicolumn{2}{c}{ Race } & \multicolumn{2}{c}{ Education } \\
\hline Month of & Max & & & & \\
Peak/Trough & difference & black & white & low & high \\
\hline
\end{tabular}

Region of birth

$\begin{array}{lllllll}\text { New England } & \text { Sep/Jun } & 0.31 & 1.47 & 0.31 & 0.45 & 0.35 \\ \text { Middle Atlantic } & \text { Sep/Jun } & 0.36 & 0.53 & 0.37 & 0.47 & 0.36 \\ \text { East North Central } & \text { Sep/Jun } & 0.46 & 0.81 & 0.45 & 0.65^{* *} & 0.34^{* *} \\ \text { West North Central } & \text { Oct/Jul } & 0.44 & 0.84 & 0.44 & 0.67^{* *} & 0.37^{* *} \\ \text { South Atlantic } & \text { Oct/Jun } & 0.46 & 0.65++ & 0.63++ & 0.53^{*} & 0.57^{*} \\ \text { East South Central } & \text { Oct/Jun } & 0.86 & 0.68++ & 1.02++ & 0.89^{*} & 0.81^{*} \\ \text { West South Central } & \text { Oct/Jun } & 0.69 & 0.97++ & 0.77++ & 0.89^{* *} & 0.58^{* *} \\ \text { Mountain } & \text { Oct/May } & 0.46 & 2.60 & 0.55 & 0.61 & 0.53 \\ \text { Pacific } & \text { Sep/Jun } & 0.42 & 1.68 & 0.42 & 0.69 & 0.33\end{array}$

All peak-to-trough differences are significant at $p<.0001$.

++ indicates significant racial differentials at $\mathrm{p}<.0001$.

** indicates significant educational differentials at $p<.0001$.

* indicates significant educational differentials at $\mathrm{p}=.05$. 
Table 3: Contribution of the interactions between month of birth and sex, education, race, marital status and region of birth to the overall model explanation of the month-of-birth effect of 0.4 per cent.

Month of birth (Mob) effect Per cent p-value

Mob 3.3 $<.0001$

$\mathrm{Mob}^{*} \operatorname{sex}$ 1.0 $<.0001$

Mob*education 8.6 $<.0001$

Mob*race 33.2 $<.0001$

Mob*marital status 17.4 $<.0001$

Mob*region of birth 36.5 $<.0001$

Total contribution of the month of birth 100.0 $<.0001$

effect $(0.4 \%)$ to the overall model explanation of $25 \%$ 
Table 4: Natural Causes of Death: Significance levels of the effect of month of birth $(\mathrm{MOB})$ and its interactions with sex, education, race, marital status and region.

\begin{tabular}{|c|c|c|c|c|c|c|c|}
\hline & \multirow{2}{*}{\multicolumn{3}{|c|}{ Model 1}} & \multirow{2}{*}{\multicolumn{3}{|c|}{$\begin{array}{c}\text { Model } 2 \\
\text { Interaction MOB with }\end{array}$}} & \multirow[b]{3}{*}{ region } \\
\hline & & & & & & & \\
\hline & Total & $\begin{array}{l}\text { Main } \\
\text { effect } \\
\text { MOB }\end{array}$ & $\operatorname{sex}$ & $\begin{array}{l}\text { edu- } \\
\text { cation }\end{array}$ & race & $\begin{array}{l}\text { marital } \\
\text { status }\end{array}$ & \\
\hline \multicolumn{8}{|l|}{ Malignant neoplasms } \\
\hline Breast & 299,323 & $<.0001$ & & & & & .0075 \\
\hline Uterus & 71,035 & .0782 & & & & & \\
\hline Prostate & 272,584 & $<.0001$ & & & & & \\
\hline Lung & $1,175,632$ & $<.0001$ & & & $<.0001$ & .0041 & $<.0001$ \\
\hline Stomach & 93,877 & .0252 & & & & & .0107 \\
\hline Colorectal & 435,972 & $<.0001$ & & & & & .0078 \\
\hline Pancreatic & 201,918 & .0443 & & & & & \\
\hline Liver & 68,710 & .0183 & & & & & \\
\hline Other & $1,328,063$ & $<.0001$ & & .0158 & $<.0001$ & .0008 & .0005 \\
\hline \multicolumn{8}{|c|}{ Circulatory disease and related diseases } \\
\hline $\begin{array}{l}\text { Acute Myocardial } \\
\text { infarction }\end{array}$ & $1,754,092$ & $<.0001$ & & .0144 & $<.0001$ & $<.0001$ & $<.0001$ \\
\hline Ischemic heart disease & $1,249,519$ & $<.0001$ & & & $<.0001$ & $<.0001$ & .0177 \\
\hline Cerebrovascular disease & $1,150,444$ & $<.0001$ & & & $<.0001$ & .0174 & .0034 \\
\hline Other circ. System & $2,971,581$ & $<.0001$ & & & $<.0001$ & $<.0001$ & $<.0001$ \\
\hline Pneumonia \& Influenza & 591,543 & $<.0001$ & & .0203 & $<.0001$ & & .0228 \\
\hline Diabetes mellitus & 400,910 & $<.0001$ & .0283 & $<.0001$ & & & \\
\hline Accidents Falls & 92,389 & .0016 & .0555 & .0307 & .0184 & & \\
\hline \multicolumn{8}{|c|}{ Other natural causes of death } \\
\hline Infectious disease & 242,155 & $<.0001$ & & & .0011 & & \\
\hline Respiratory system & 998,388 & $<.0001$ & & & .0039 & .0027 & .0167 \\
\hline Digestive system & 523,268 & $<.0001$ & & & $<.0001$ & & \\
\hline Other natural causes & 776,124 & $<.0001$ & & & $<.0001$ & & .0008 \\
\hline \multicolumn{8}{|c|}{ Diseases of the nervous and mental system } \\
\hline Parkinson & 75,016 & .0011 & & & & .0003 & \\
\hline Multiple sclerosis & 12,038 & & & & & & \\
\hline Other nervous system & 100,482 & .0017 & & & & & \\
\hline Schizophrenia & 2,459 & .0382 & & & .0062 & .0101 & \\
\hline Dementia & 112,690 & .0081 & & & & .0345 & \\
\hline Alzheimer & 139,188 & $<.0001$ & & .0118 & & & \\
\hline Other mental disorders & 124,167 & $<.0001$ & & & & & \\
\hline
\end{tabular}


Table 5: Non-natural Causes of Death: significance levels of the effect of month of birth $(\mathrm{MOB})$ and its interactions with sex, education, race, marital status and region.

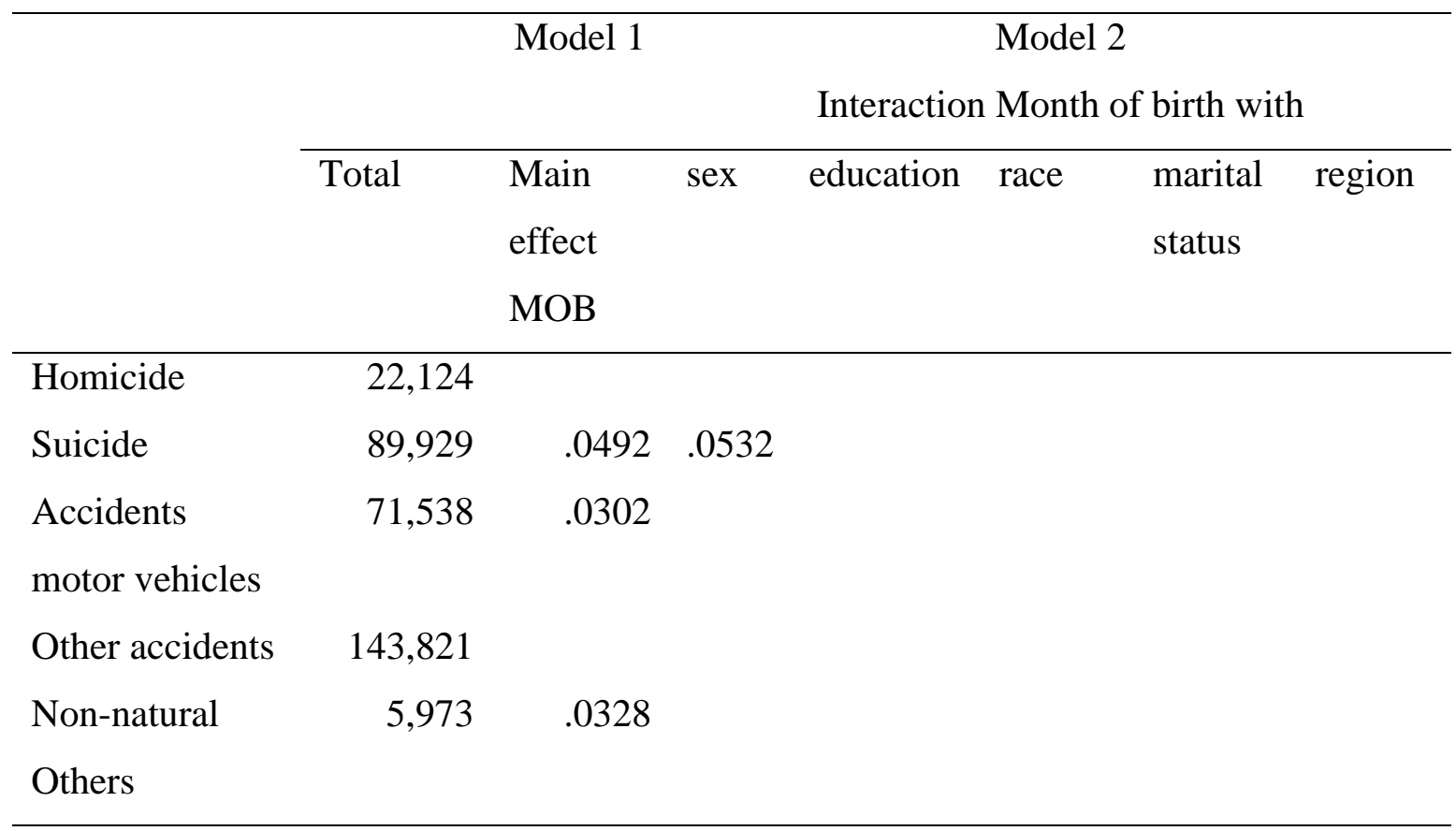

Model 1 includes main effects of month of birth (MOB), education, race, region, marital status and sex. All main effects are highly significant.

Model 2 includes all main effects and all interaction effects significant at a level of 0.05 . The main effect of month of birth is significant for all causes of death. 
Figure 1: Scatterplots of the maximum difference in mean age at death and temperature for the 48 contiguous states of the US.

Minimum Temperature

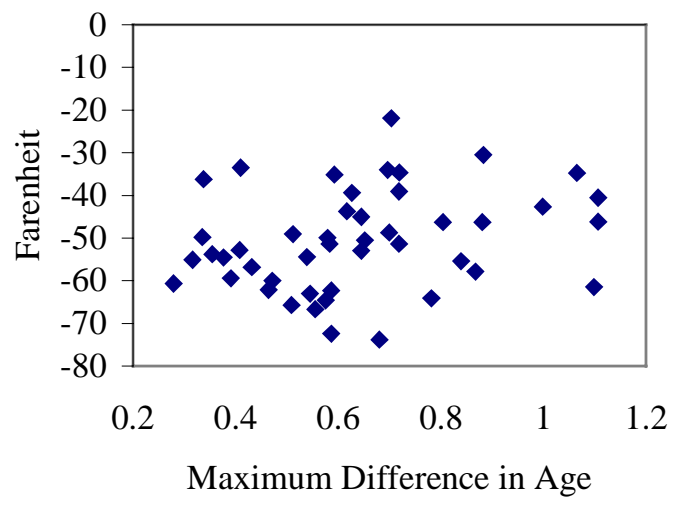

Maximum Difference in Temperature

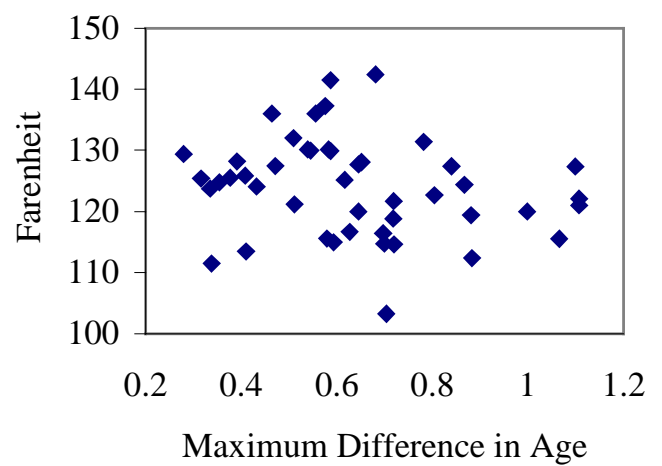

Maximum Temperature

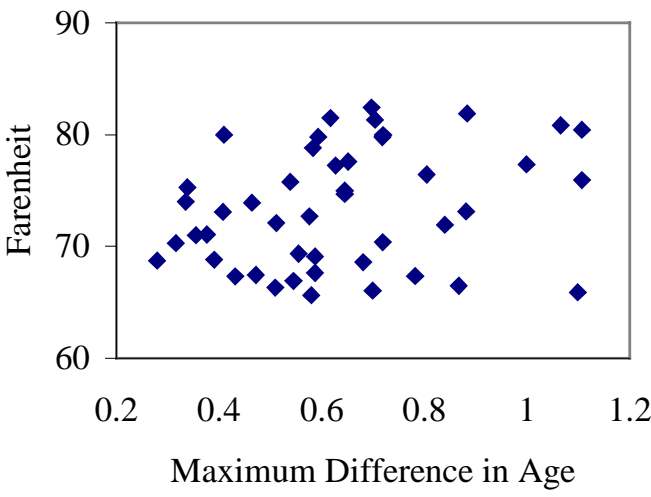

Latitude

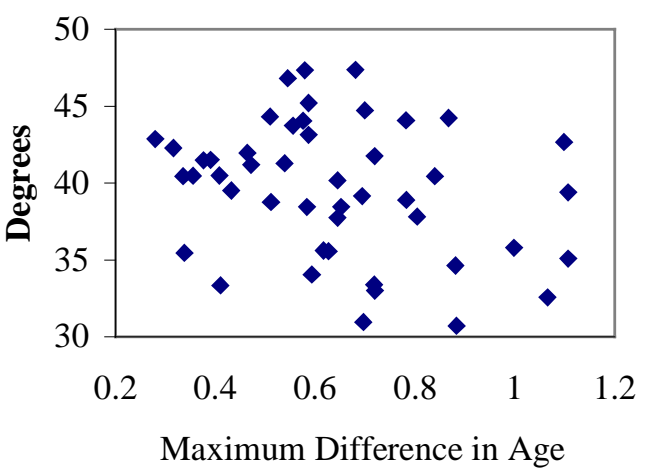


Figure 2: Educational differentials in the deviations of mean age at death of decedents born in a specific month from average mean age at death; US death records 1989 to 1997 , ages 50-100.

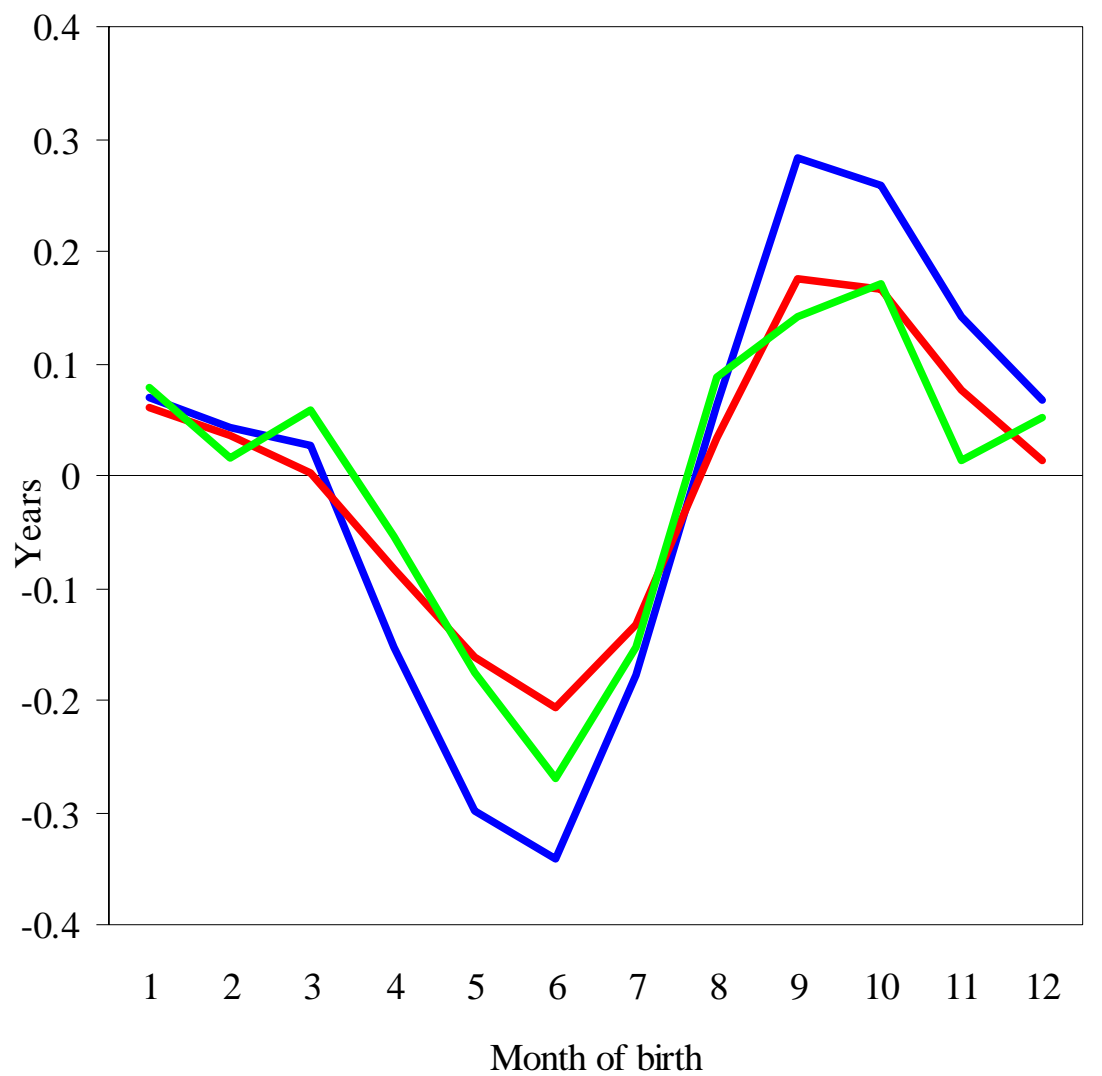

age standardized - low - high - unknown 
Figure 3: Racial differentials in the deviations of mean age at death of decedents born in a specific month from average mean age at death; US death records 1989 to 1997, ages 50100.

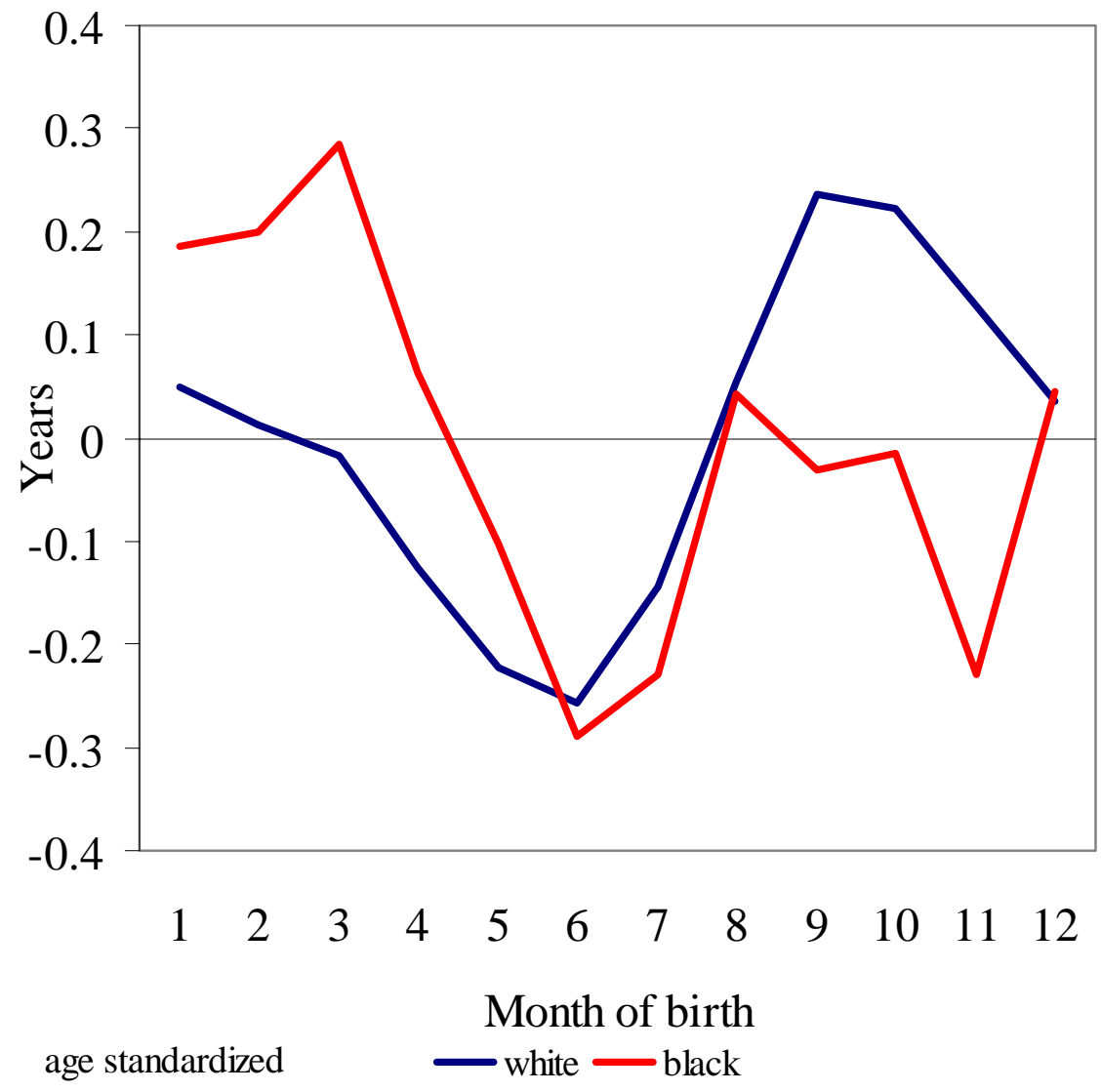


Figure 4: Deviation of mean age at death of decedents born in a specific month from average mean age at death by region of birth and education: US death records 1989 to 1997, ages 50-100.
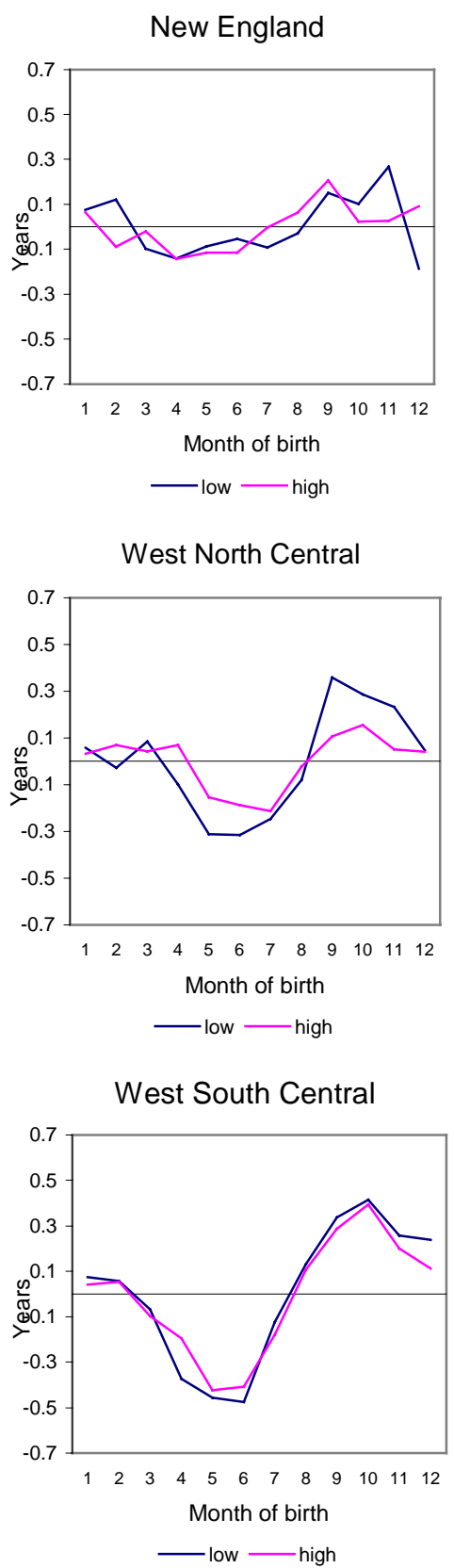

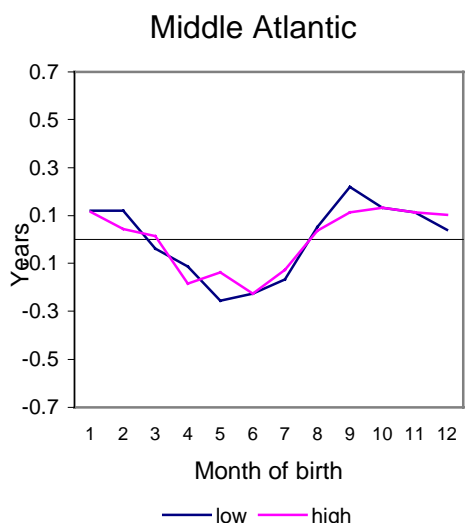

South Atlantic

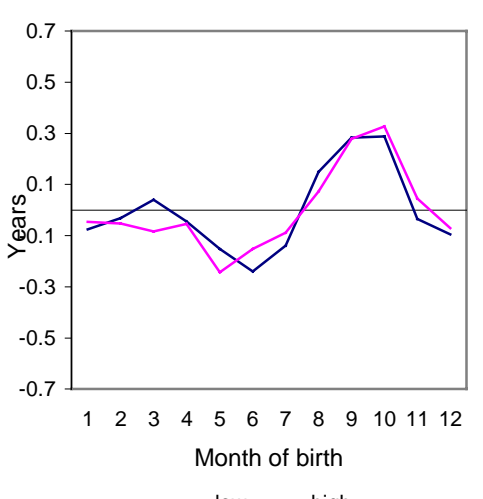

- low - high

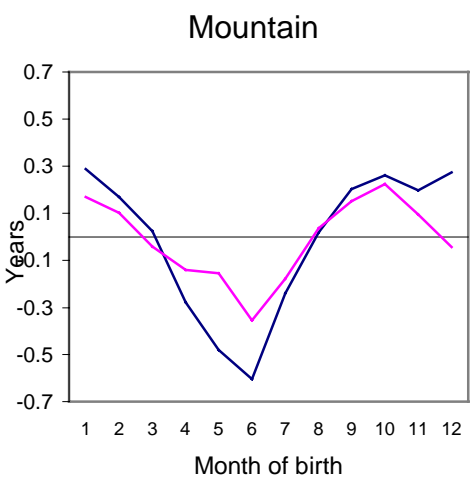

—low - high

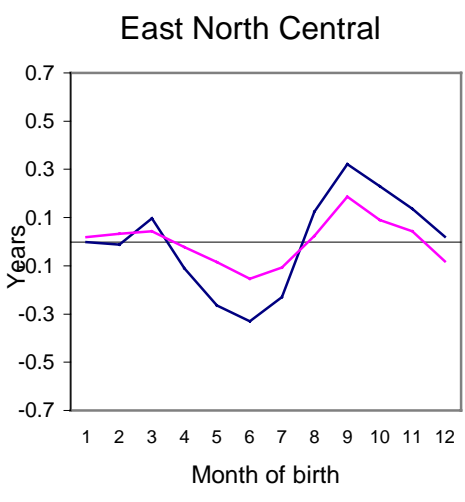

- low —high

East South Central

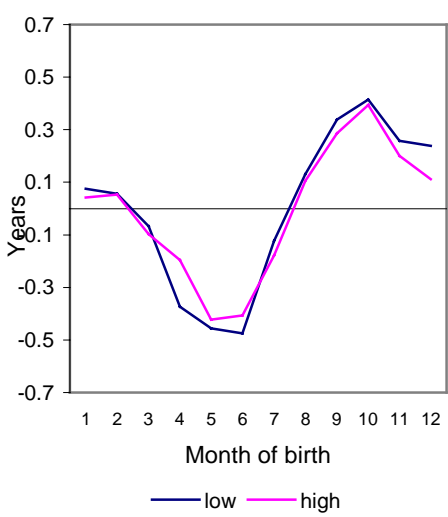

Pacific

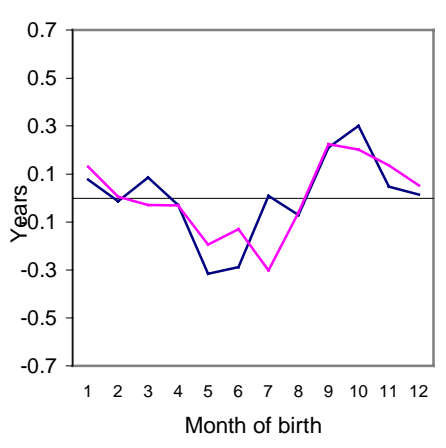


Figure 5: Deviation of mean age at death of decedents born in a specific month from average mean age at death by region of birth and race: US death records 1989 to 1997, ages 50-100.

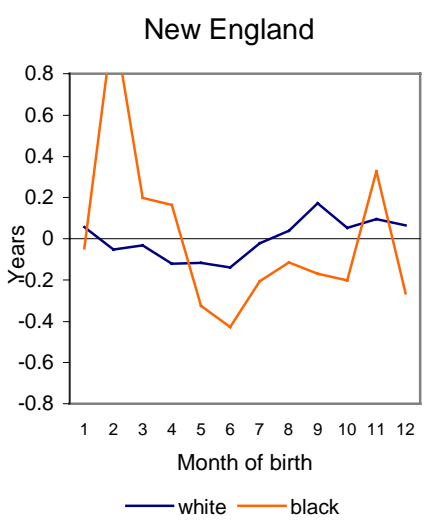

West North Central

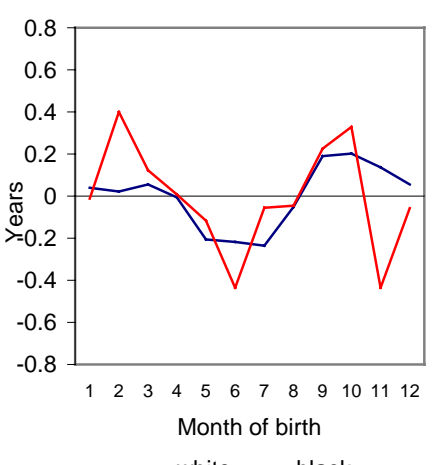

East South Central

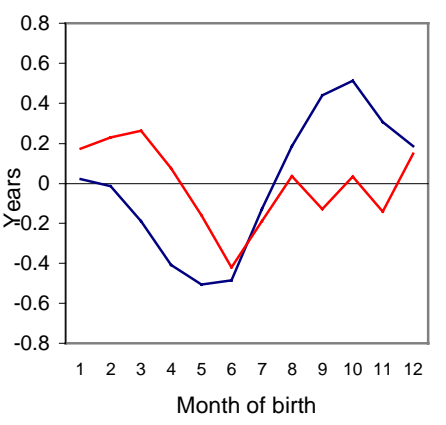

— white - black
Middle Atlantic

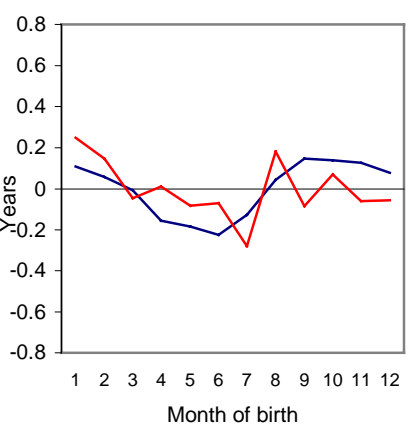

- white — black

South Atlantic

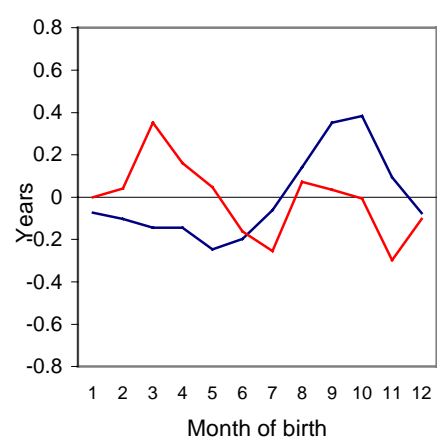

- white - black

Mountain

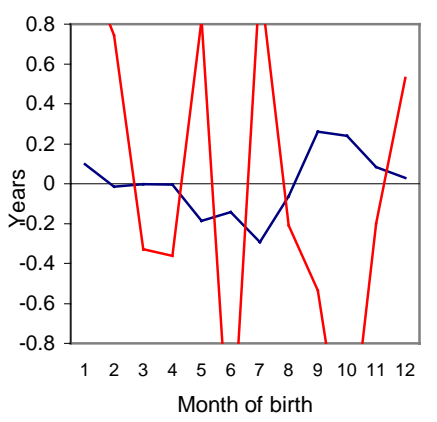

- white - black
East North Central

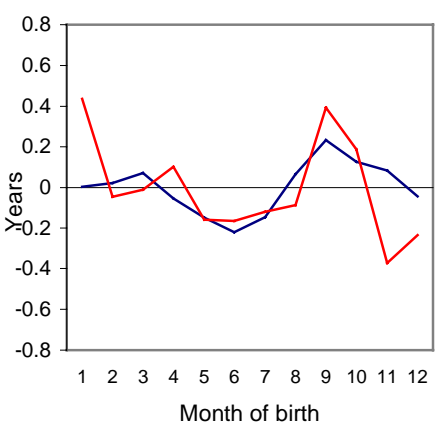

— white — black

West South Central

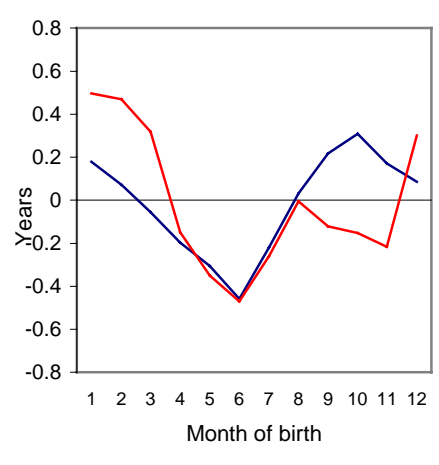

— white — black

Pacific

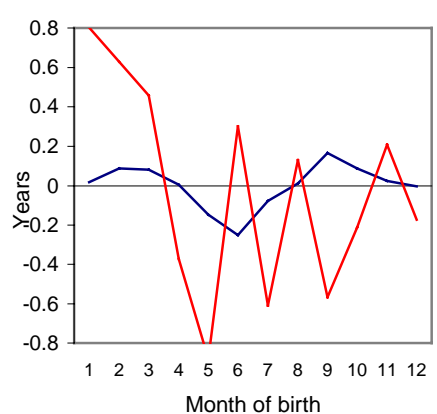


Figure 6: Deviation of mean age at death of decedents born in a specific month from average mean age at death by marital status: US death records 1989 to 1997, ages 50-100.

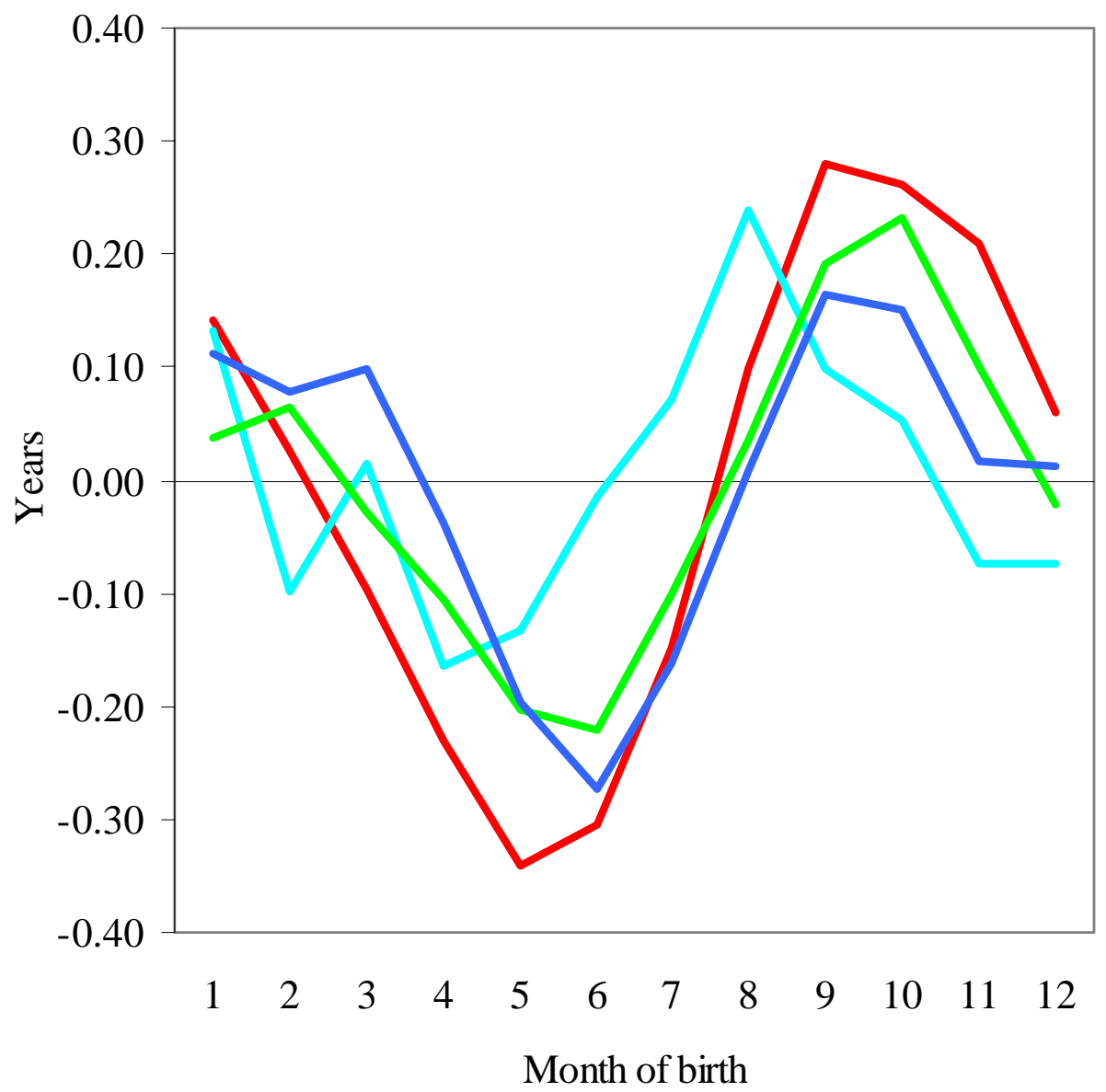

never married $\longrightarrow$ married $\longrightarrow$ widowed $\longrightarrow$ divorced 
Figure 7: Malignant Neoplasms by Race: Deviation of mean age at death of decedents born in a specific month from average mean age at death: US death records 1989 to 1997 , ages 50-100.
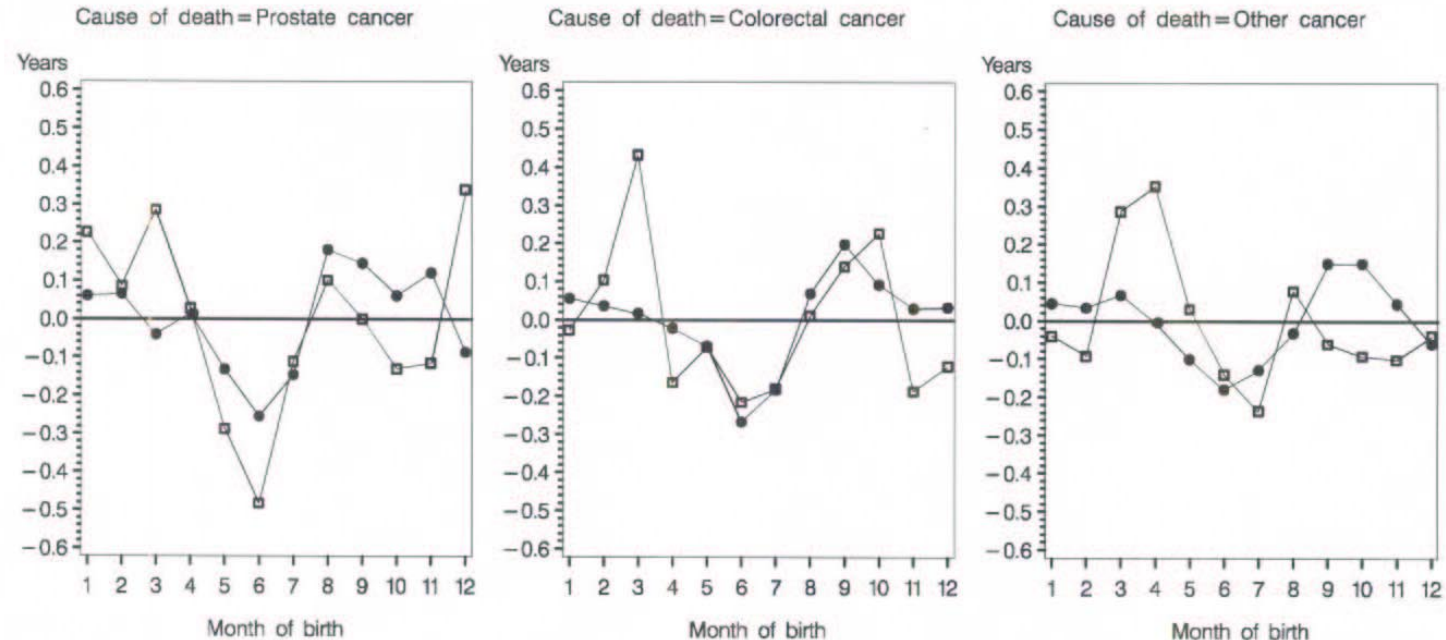

Cause of death $=$ Uterus cancer

Cause of death $=$ Stomach cancer

Cause of death = Liver cancer
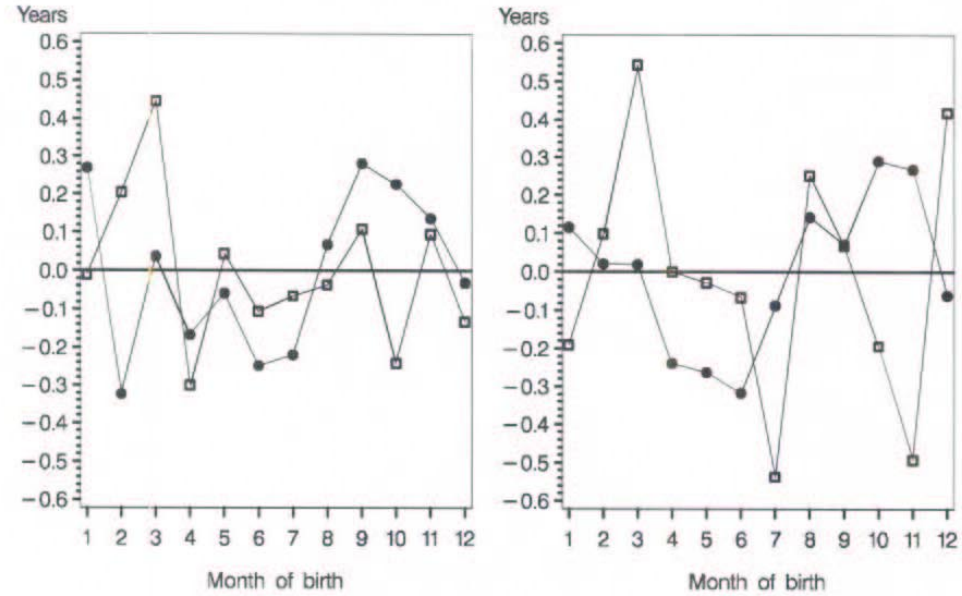

Cause of death $=$ Breast cancer

Cause of death $=$ Lung cancer

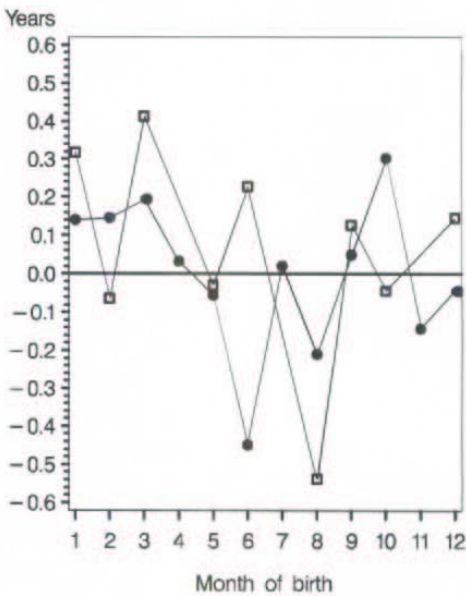

Cause of death $=$ Pancreatic cancer
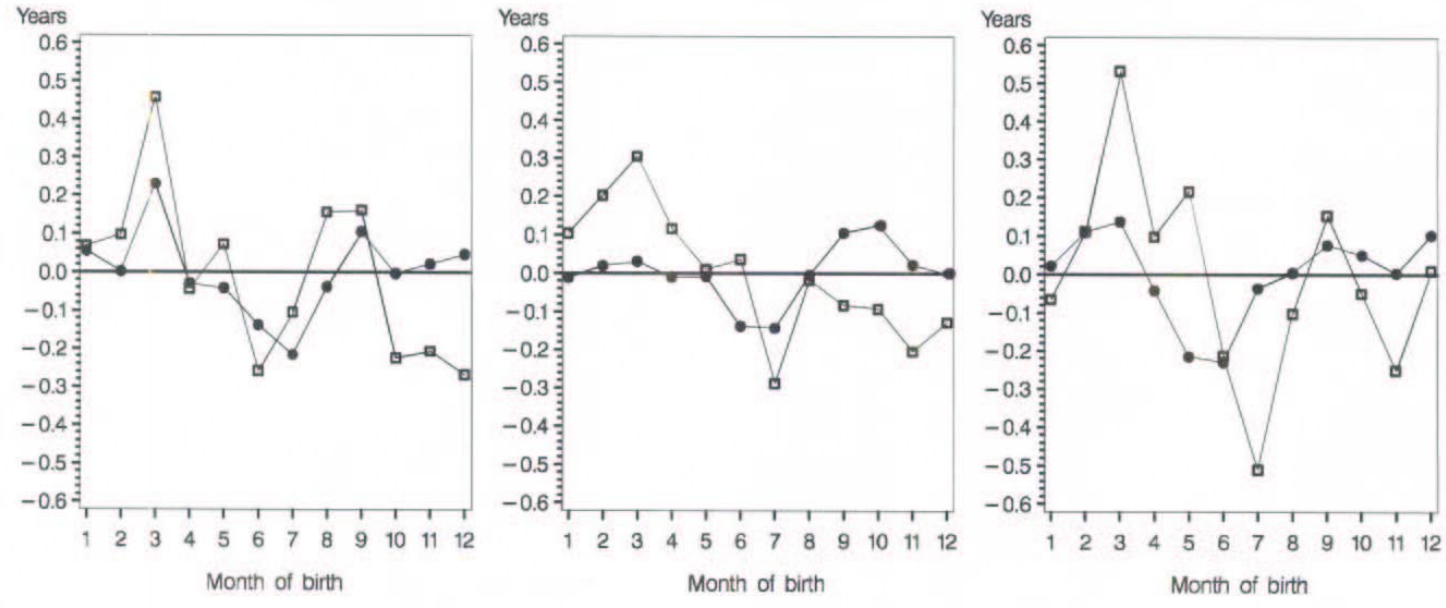

Race

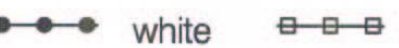

black 
Figure 8: Lung Cancer by Marital Status: Deviation of mean age at death of decedents born in a specific month from average mean age at death: US death records 1989 to 1997 , ages 50-100.
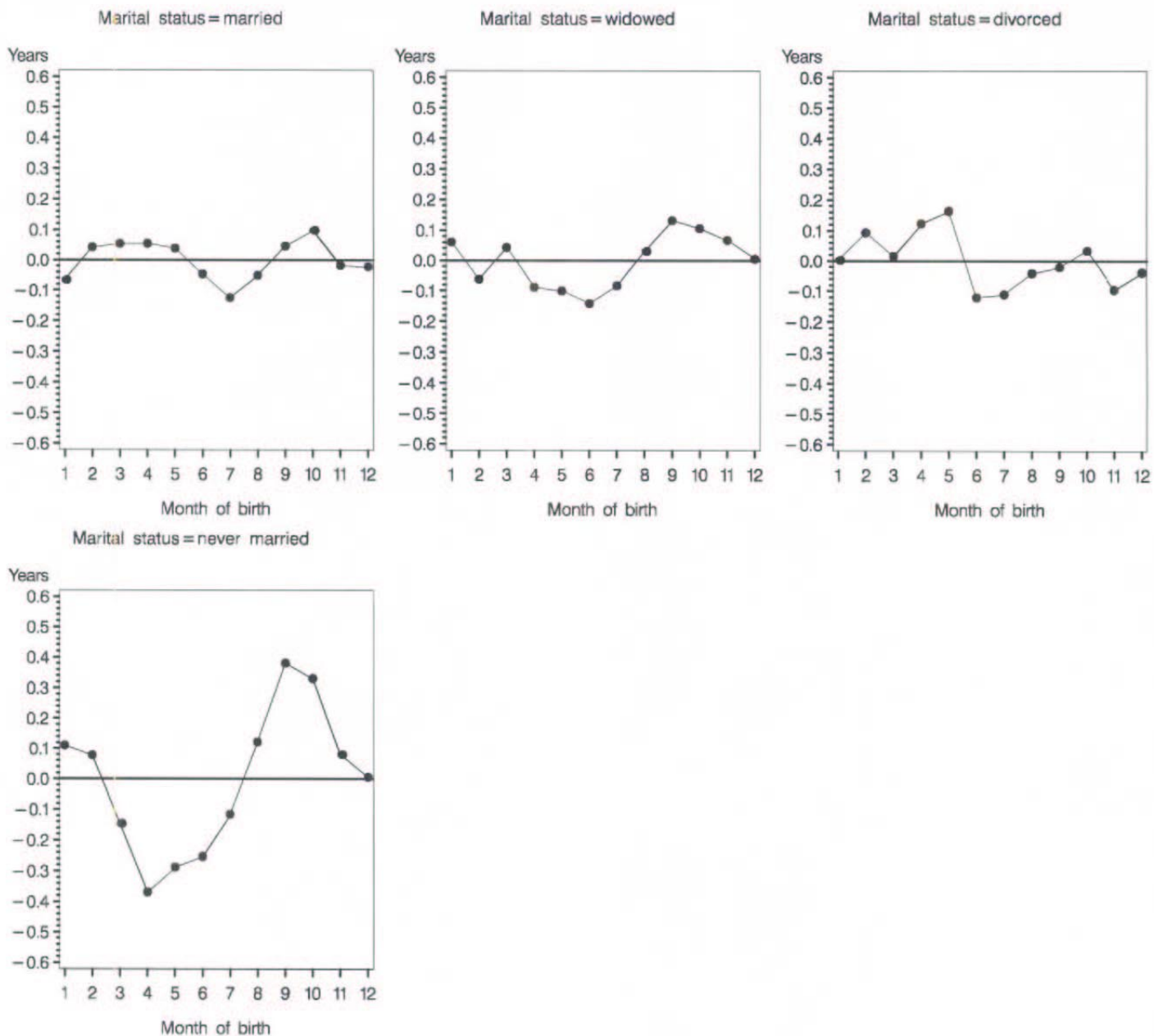
Figure 9: Lung Cancer by Region: Deviation of mean age at death of decedents born in a specific month from average mean age at death: US death records 1989 to 1997, ages 50100.

Birth region = New England

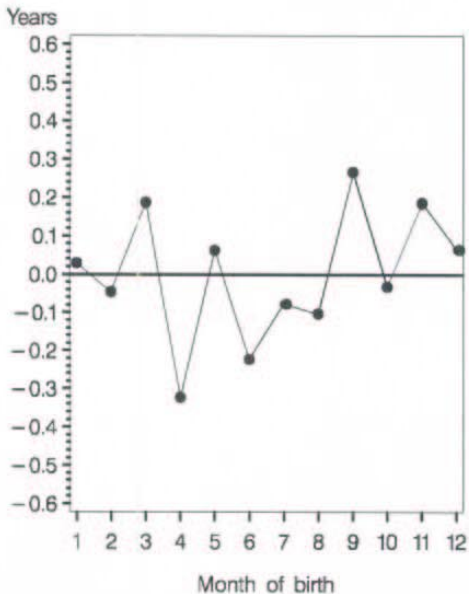

Birth region $=$ West North Central

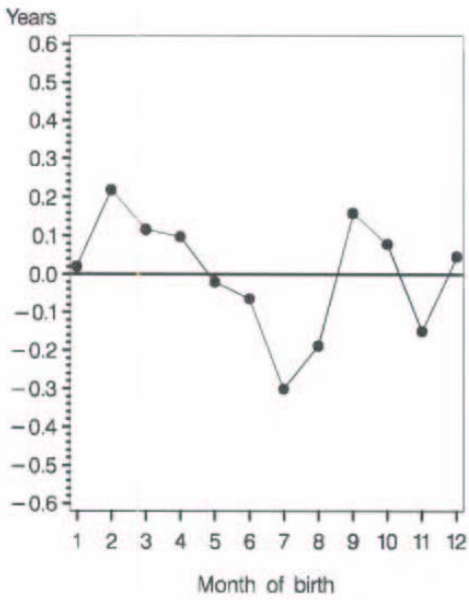

Birth region $=$ West South Central

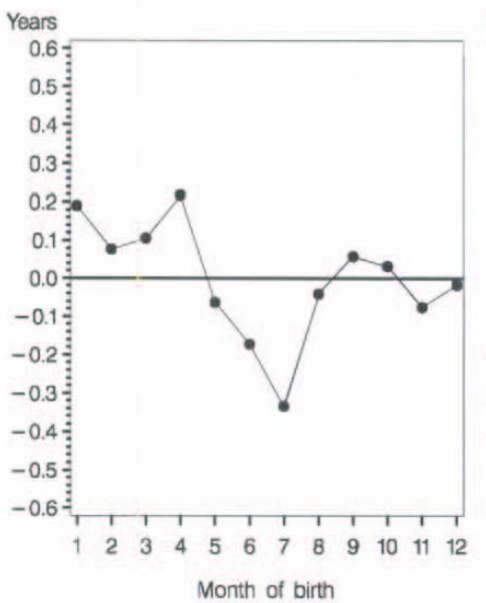

Birth region=Middle Atlantic

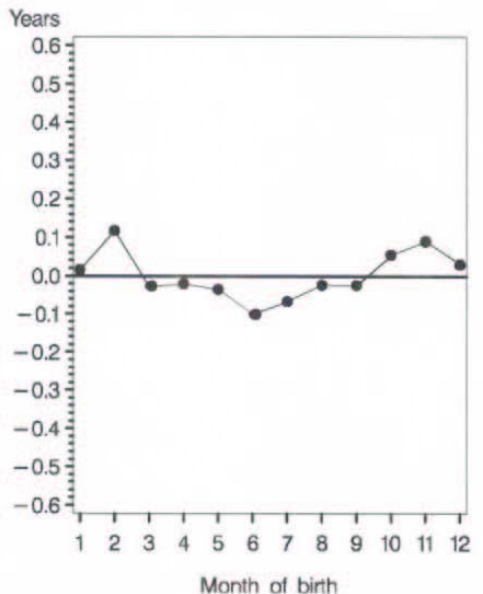

Birth region=South Atlantic

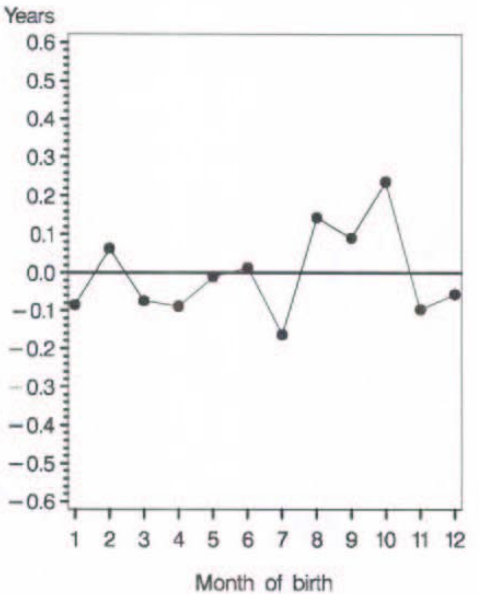

Birth region= Mountain

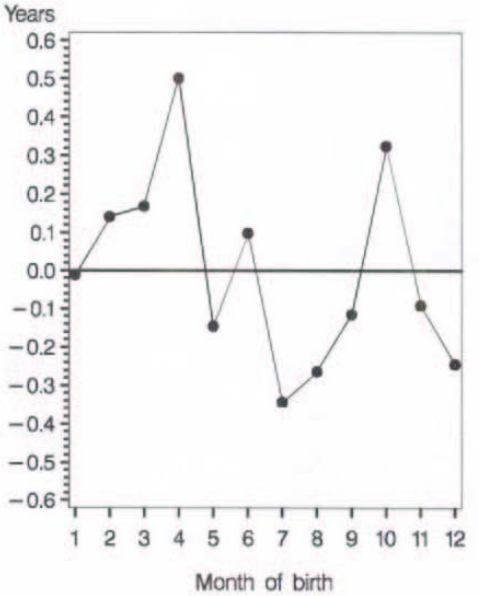

Birth region $=$ East North Central

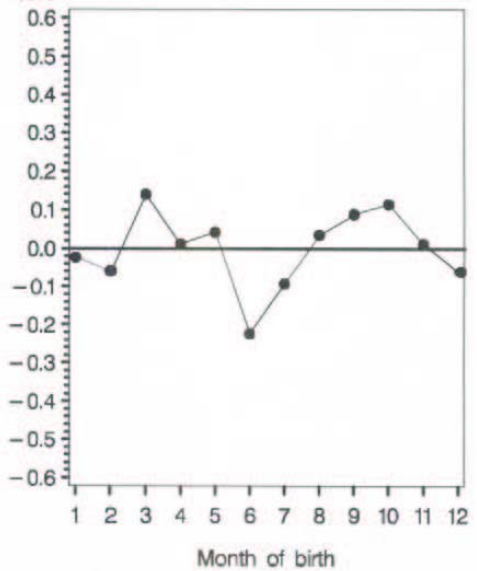

Birth region $=$ East South Central

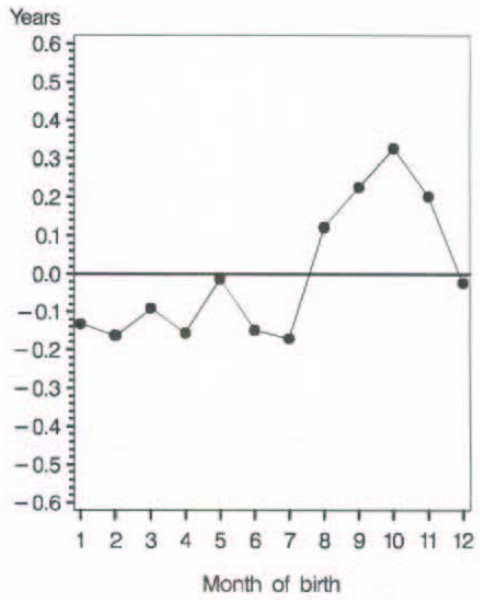

Birth region $=$ PAcific

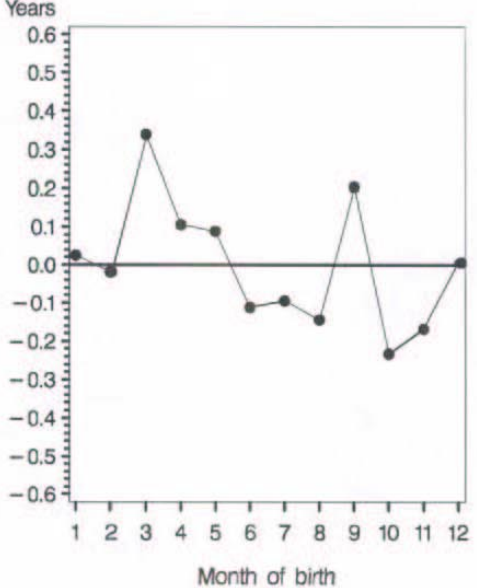


Figure 10: Diseases of the Circulatory system by race: Deviation of mean age at death of decedents born in a specific month from average mean age at death: US death records 1989 to 1997 , ages 50-100.

Cause of death $=$ Ischemic heart disease

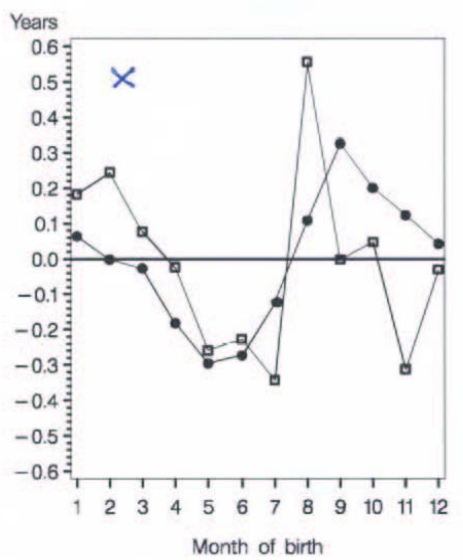

Cause of death $=$ Acute Myocardia

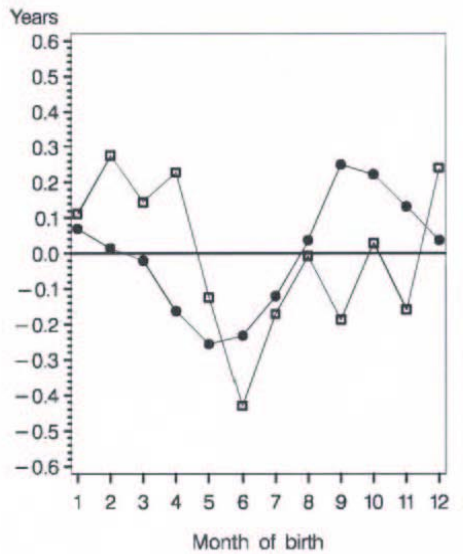

Cause of death $=$ Circ. system others

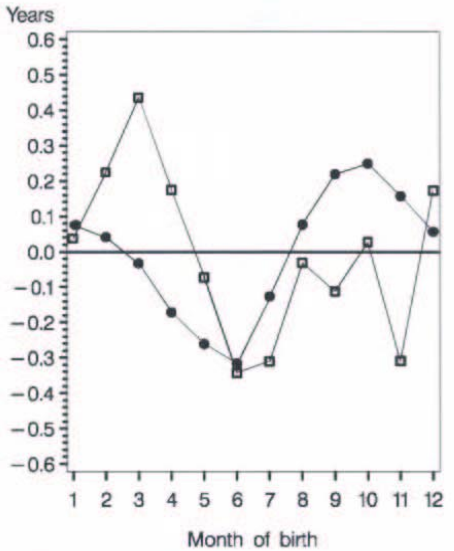

Cause of death $=$ Cerebrovasc. . disease

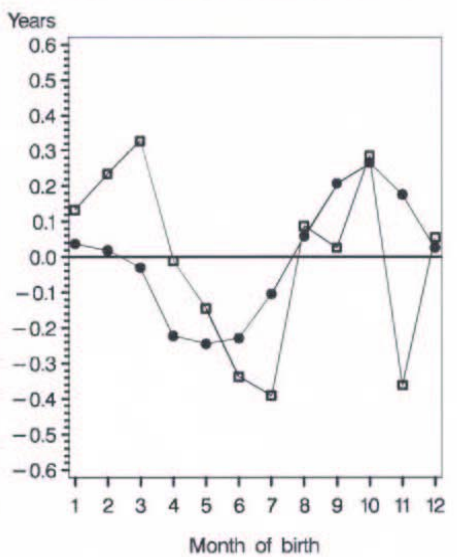

Cause of death $=$ Falls

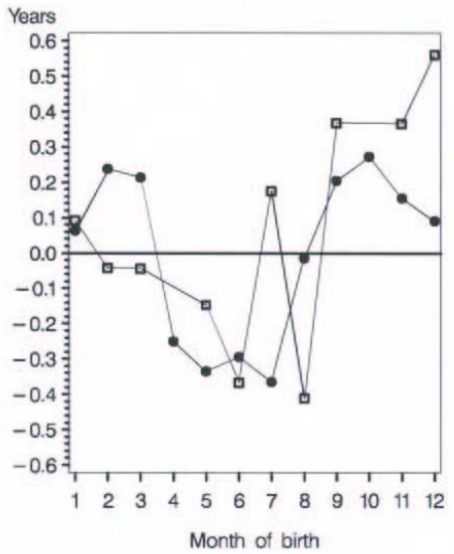

Cause of death $=$ Diabetis mellitus

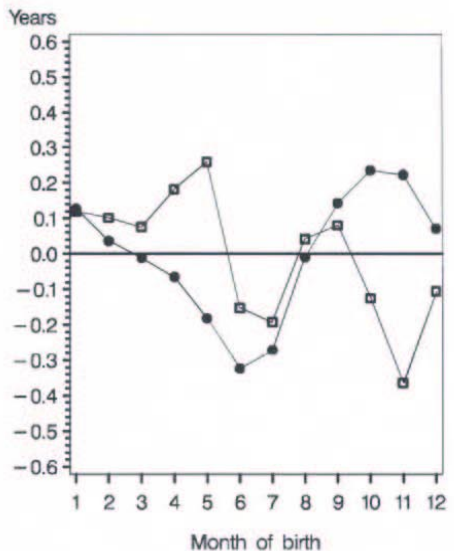


Figure 11: Other Natural and non-natural causes of death: Deviation of mean age at death of decedents born in a specific month from average mean age at death: US death records 1989 to 1997 , ages 50-100.
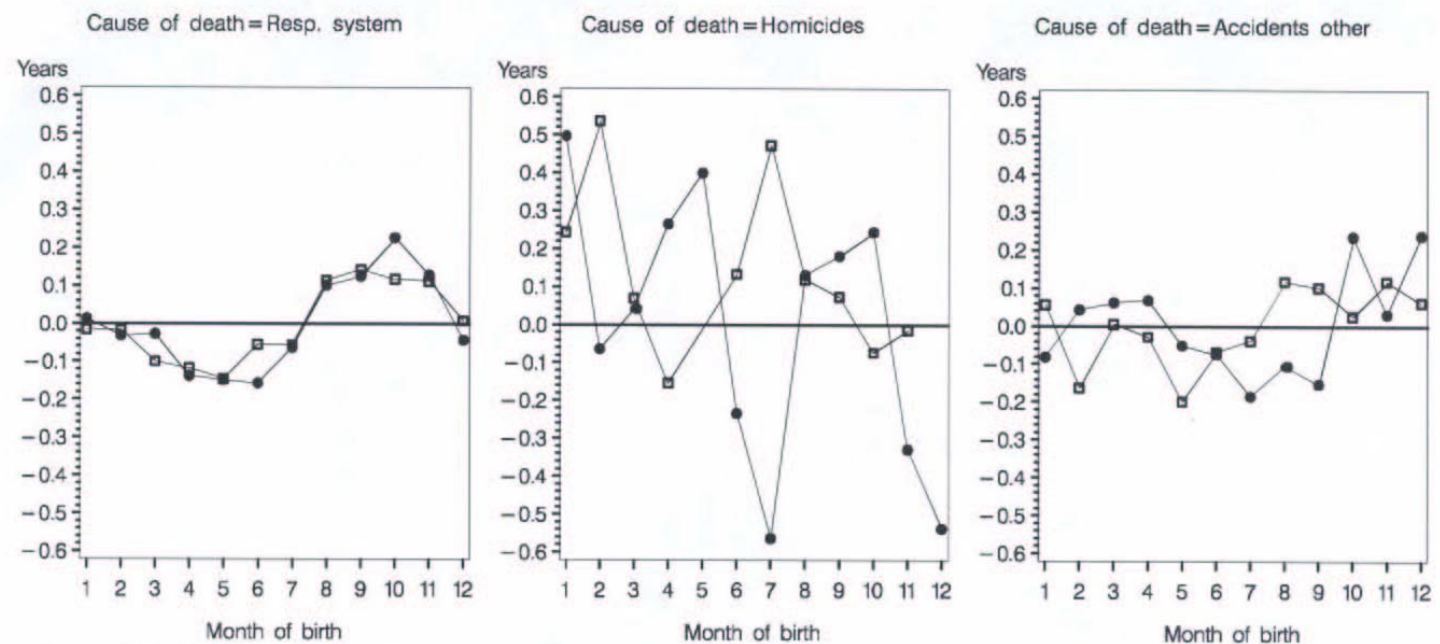

Cause of death=Pneumonia \& influenza

Cause of death $=$ Natural others

Cause of death $=$ MTV accidents

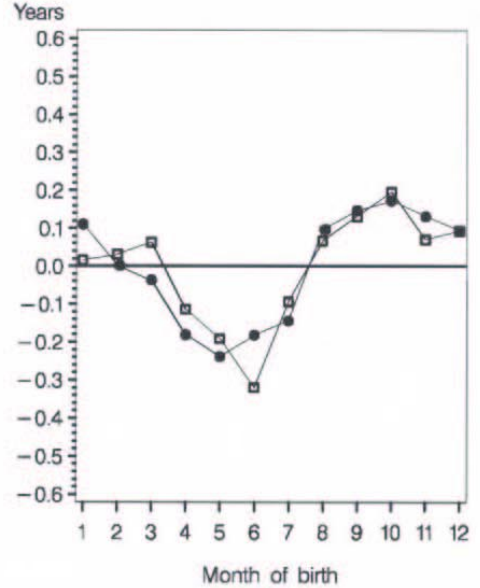

Cause of death $=$ Infectious disease

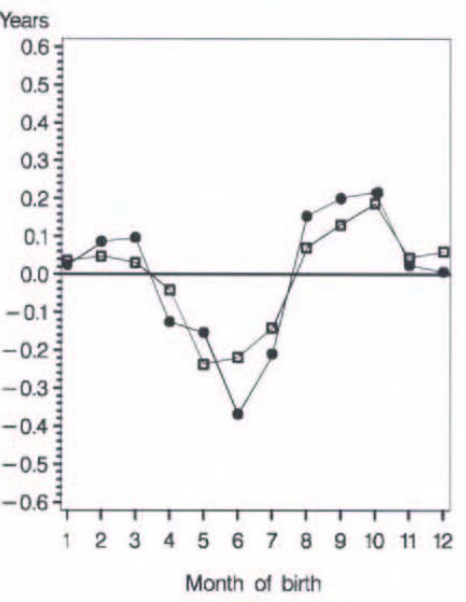

Cause of death $=$ Digestive system
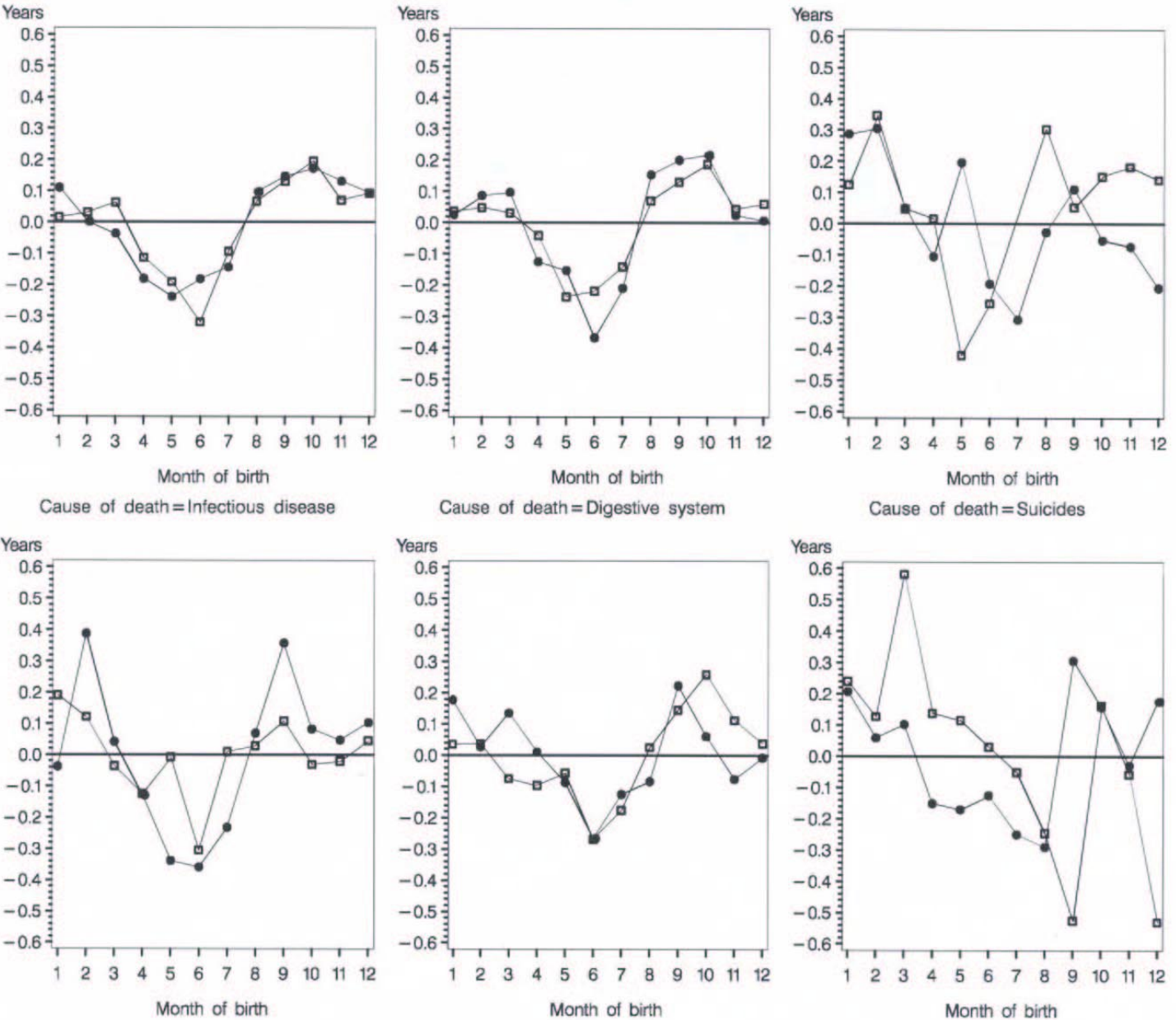
Years

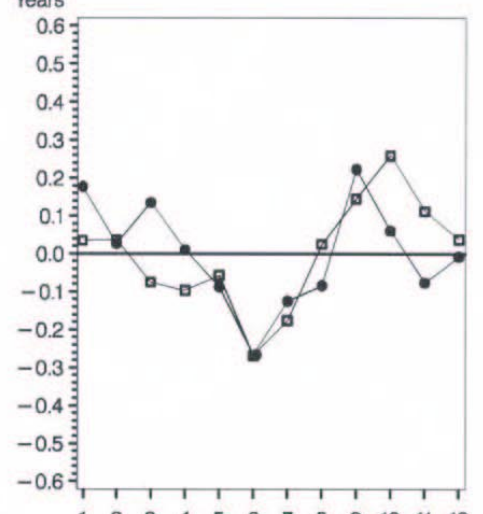

Cause of death $=$ Suicides

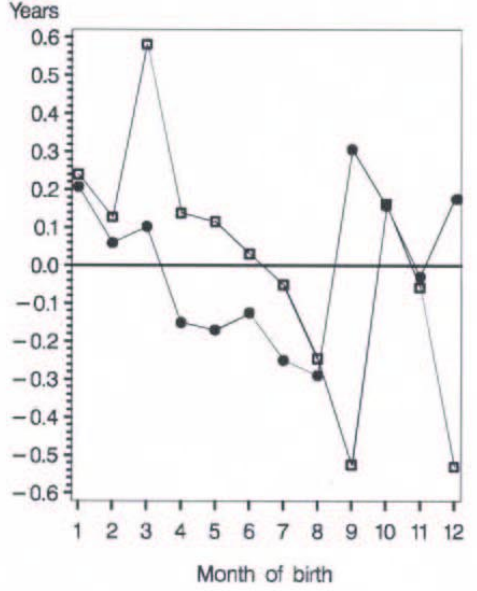

Sex 
Figure 12: Nervous and Mental Disorders: Deviation of mean age at death of decedents born in a specific month from average mean age at death: US death records 1989 to 1997 , ages 50-100.

Cause of death $=$ Nerv . systen others

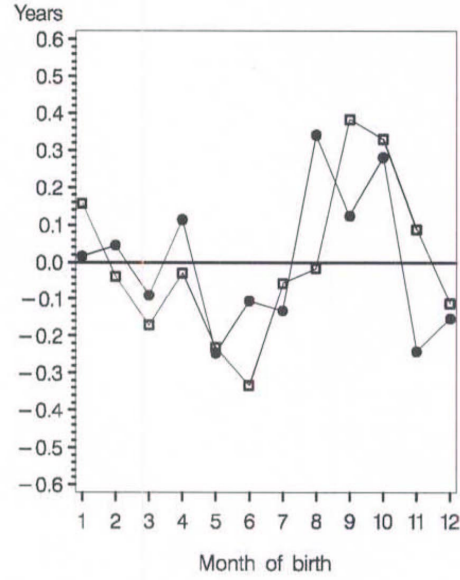

Cause of death $=$ Parkinson

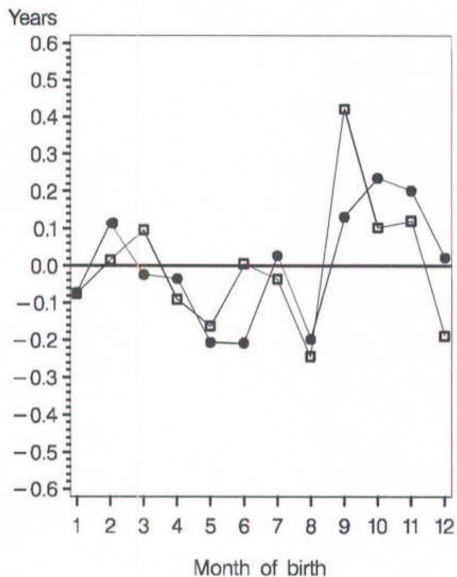

Cause of death $=$ Alzheimer

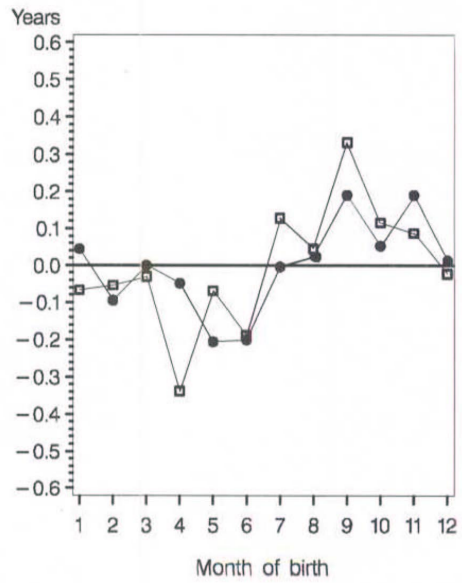

Cause of death $=$ Dementia

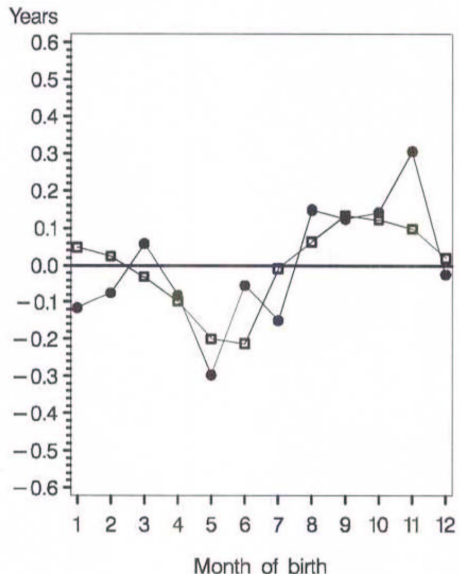

Cause of death $=$ Schizophrenia

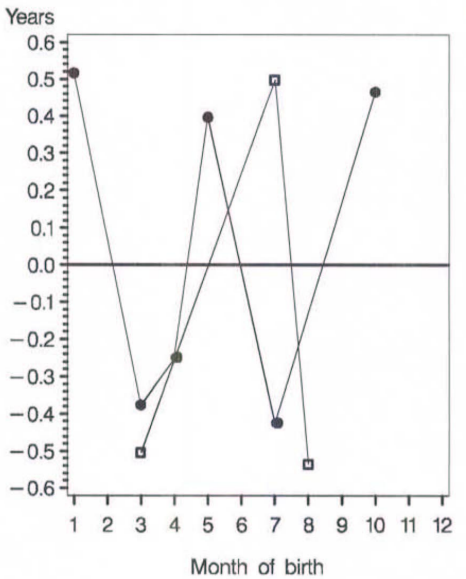

Cause of death $=$ Multiple Sclerosis

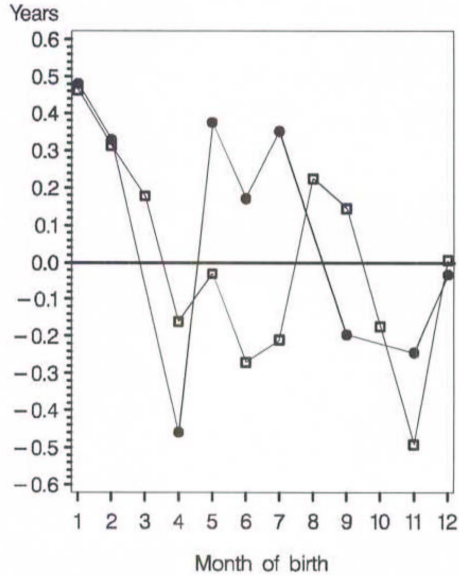

Cause of death $=$ Mental disorder oth .

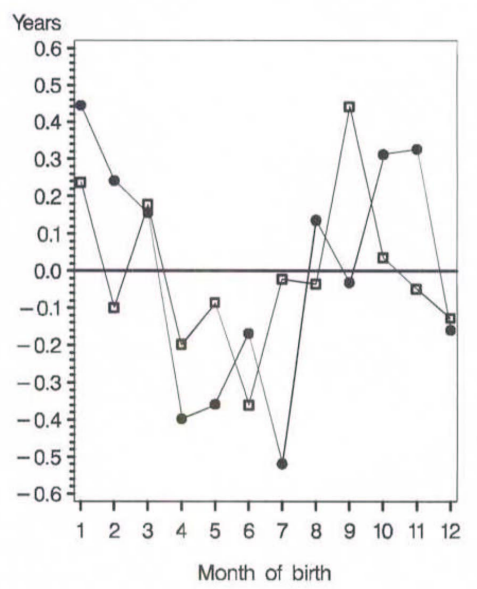

Sex 